Review

\title{
Epigenetic and Posttranslational Modifications in Light Signal Transduction and the Circadian Clock in Neurospora crassa
}

\author{
Marco Proietto ${ }^{1}$, Michele Maria Bianchi ${ }^{1}$, Paola Ballario ${ }^{1,2}$ and Andrea Brenna ${ }^{1,2,3, *}$ \\ 1 Department of Biology and Biotechnologies "Charles Darwin”, Sapienza-University of Rome, \\ Piazzale Aldo Moro 5, Rome 00185, Italy; E-Mails: marco.proietto@uniroma1.it (M.P.); \\ michele.bianchi@uniroma1.it (M.M.B.); paola.ballario@uniroma1.it (P.B.) \\ 2 Pasteur Institute, Cenci Bolognetti Foundation and Department of Biology and Biotechnology \\ “Charles Darwin”, Sapienza-University of Rome, Piazzale Aldo Moro 5, Rome 00185, Italy \\ 3 Department of Biology, Division of Biochemistry, University of Fribourg, Chemin du Musée 5, \\ Fribourg 1700, Switzerland \\ * Author to whom correspondence should be addressed; E-Mail: andrea.brenna@unifr.ch; \\ Tel.: +41-26-300-8638.
}

Academic Editor: Nicholas Delihas

Received: 12 May 2015 / Accepted: 30 June 2015/ Published: 7 July 2015

\begin{abstract}
Blue light, a key abiotic signal, regulates a wide variety of physiological processes in many organisms. One of these phenomena is the circadian rhythm presents in organisms sensitive to the phase-setting effects of blue light and under control of the daily alternation of light and dark. Circadian clocks consist of autoregulatory alternating negative and positive feedback loops intimately connected with the cellular metabolism and biochemical processes. Neurospora crassa provides an excellent model for studying the molecular mechanisms involved in these phenomena. The White Collar Complex (WCC), a blue-light receptor and transcription factor of the circadian oscillator, and Frequency (FRQ), the circadian clock pacemaker, are at the core of the Neurospora circadian system. The eukaryotic circadian clock relies on transcriptional/translational feedback loops: some proteins rhythmically repress their own synthesis by inhibiting the activity of their transcriptional factors, generating self-sustained oscillations over a period of about $24 \mathrm{~h}$. One of the basic mechanisms that perpetuate self-sustained oscillations is post translation modification (PTM). The acronym PTM generically indicates the addition of acetyl, methyl, sumoyl, or phosphoric groups to various types of proteins. The protein can be regulatory or enzymatic or a component of the chromatin. PTMs influence protein
\end{abstract}


stability, interaction, localization, activity, and chromatin packaging. Chromatin modification and PTMs have been implicated in regulating circadian clock function in Neurospora. Research into the epigenetic control of transcription factors such as WCC has yielded new insights into the temporal modulation of light-dependent gene transcription. Here we report on epigenetic and protein PTMs in the regulation of the Neurospora crassa circadian clock. We also present a model that illustrates the molecular mechanisms at the basis of the blue light control of the circadian clock.

Keywords: phosphorylation; acetylation; methylation; chromatin remodeling; light signal transduction; circadian rhythms; Neurospora crassa

\section{The Neurospora crassa Light Responses}

\subsection{Light Signal Transduction}

Exposure to environmental light stimulates physiological responses in all living organisms, from prokaryotes to eukaryotes [1]. Studies in plants have identified photoreceptors that respond to two types of light signals: blue light and red light [2-4]. Although plants were the first organisms in which molecular mechanisms of light signal transduction were characterized, the Ascomyceta filamentous fungus Neurospora crassa represents the most used model system. $N$. crassa is sensitive only to blue light, although genes coding for other putative photoreceptors have been identified [5,6]. Nevertheless, it seems that the deletion of these genes does not cause aberration in response to blue light stimulation [7]. Blue light exposure induces many different physiological responses in $N$. crassa, including entrainment, biosynthesis of photo protective pigments, induction of asexual conidiospores formation, phototropism of peritecial beaks, development of sexual structures, and the direction of ascospore dispersal [8-13]. Several genes coding for proteins activated in response to light stimulation have been identified $[14,15]$. Genome-wide analysis shows that approximately $5.6 \%$ of the protein-coding genes in $N$. crassa are responsive to light [16]. Light-sensitive genes are grouped in two large classes: early light-responders (ELR), with average peaks in mRNA expression at approximately 15 to $30 \mathrm{~min}$, and late light-responders (LLR) in which mRNA expression peaks between 60 and $90 \mathrm{~min}$ [17].

\subsection{White Collar Complex (WCC) Activation}

The light signaling system is regulated by the White Collar complex (WCC). The WCC consists of a heterodimer formed by the product of the white collar-1 (wc-1) and white collar-2 (wc-2) genes [18,19]. WC-1 and WC-2 contain Per-ARNT-Sim (PAS) domains, which serve as versatile sensor and interaction modules in signal transduction for protein-protein interaction [20]. The WC-1 first PAS is a modified domain known as the light-oxygen-voltage domain (LOV), which is a PAS domain variant initially found in phototropins, a family of blue-light sensitive plant photoreceptors (Figure 1a) [21]. This domain is able to bind chromophores such as Flavin Adenine Dinucleotide (FAD) makingWC-1 a "photoreceptor": when a chromophore captures photons, it generates a photo-adduct with the LOV 
domain, which changes WC-1 conformation and promotes signal transmission [22]. Like its molecular partner WC-1, WC-2 shares the same functional domains except the LOV domain (Figure 1b).

a)

\begin{tabular}{|l|l|l|l|l|l|l|l|l|}
\hline & LOV & & PAS & LXXLL & PAS & LXXLL & ZnF & \\
\hline
\end{tabular}

b)

\begin{tabular}{|c|c|}
\hline PAS & $\mathrm{ZnF}$ \\
\hline
\end{tabular}

Figure 1. Domains composing White Collar 1 (a) and White Collar 2 (b). Legend: LOV domain: Light-Oxygen-Voltage sensitive domain; LXXLL: WC-1/NGF1 interaction domains; PAS domain: Per Arnt Sim domain dimerization domain; Zn finger: Zinc finger, DNA binding domain.

WC-1 heterodimerizes with WC-2 to form the WCC, which then translocates into the nucleus where it mediates conformational changes when a light signal is perceived and activates the transcription of hundreds of target genes [23]. Both WC-1 and WC-2 proteins can bind promoter sequences called Light Responsive Elements (LREs) by their zinc-finger motifs. The LREs promoter sequences contain GATC/G consensus sequences. These regions were recognized by in vitro binding assays using recombinant WC-1 and WC-2 zinc-finger domains or activated WCC [24]. WCC is able to homodimerize via the activated LOV domain and binds preferentially to tandem GATC motifs in the presence or absence of light [24,25]. Nevertheless, within only $15 \mathrm{~min}$ after light pulse, WCC transiently activates early light-responsive genes such as albino-3, vivid, and frequency triggering a long-term mechanism [26,27]. The transcription factor SUB-1 supports recruitment of -light-activated WCC to some promoters of its own target genes [25]. Moreover, many light-regulated genes are under delayed transcriptional control mediated by WCC and are expressed several hours after light induction [28-30]. WCC also acts as an inhibitor of $w c-2$ transcription [26]. This inhibition is regulated via an unidentified repressor of $w c-2$ transcription, which is expressed under the control of WCC [31]. After exposure to a light pulse, another factor that can modify WCC activity is Vivid, which is rapidly transcribed and translated. VIVID (VVD) is a small flavin PAS/LOV protein that binds blue-light photoreceptors [32,33]. It is involved in photoadaptation in Neurospora. Vivid inhibits WCC in a light-dependent fashion. The light-activated VVD acts as a competitive inhibitor of WCC homodimerization via its own LOV domain. It dampens the level of oscillating light-dependent transcripts, reverting them to the pre-induction phase (constant darkness) within 2 to $4 \mathrm{~h}$ after light exposure [34,35].

\section{The Neurospora crassa Circadian Cycle}

Circadian rhythms consist of daily physiological cycles driven by an endogenous biological clock and are entrained by zeitgebers, exogenous stimuli such as light, temperature, and nutrients [36]. These biological cycles are found in all living organisms from prokaryotes to mammals and are regulated by a molecular mechanism that is highly conserved across species [37]. Present at all levels of tissue organization, circadian rhythms are generated by individual cells and persist in the absence of external stimuli. Together with Drosophila and the mouse, $N$. crassa is a commonly used model system in the study of circadian rhythms [38,39]. The first documented Neurospora circadian rhythm 
was discovered in 1960 and was characterized as a sustained period of $22.5 \mathrm{~h}$ under constant conditions, roughly matching the Earth's 24 h rotation cycle [40].

A variety of Neurospora mutants have been studied to better understand these rhythms, assigning them such rhythmic-inspired terms as patch, clock and wrist watch, timex and band [41-44]. Rhythmic spore formation can be easily monitored during growth as a pattern of thick conidiation "bands" alternating with thin "interbands" as the fungal mycelium advances across a solid agar surface and it is used as a phenotypic control of Neurospora circadian synchronization [45]. Frq is one of the genes transcribed after WCC activation [46]. It is the principal repressor involved in the negative loop of the circadian clock system [47]. Since frq is rapidly activated after multiple light pulses, FRQ also influences the light dependent gene transcription [48]. Light/Dark transition leads to a rapid disappearance of frq RNA and degradation of FRQ protein and WCC reactivation [49].

\section{Positive and Negative Feedback Loops in the Neurospora's Circadian Clock}

The current model describing the molecular mechanism driving the circadian rhythm in $N$. crassa consists of interlocked negative and positive feedback loops involving the clock genes frq, wc-1, and $w c-2$ [46]. In constant darkness, WCC (D-WCC) acts on the positive loop and activates the transcription of the frq gene encoding the FRQ protein which binds its own C-box [50-52]. After frq gene transcription, frq mRNA reaches its peak during the subjective day, and FRQ protein peaks 4 to $6 \mathrm{~h}$ later. It was found that frq mRNA possesses another start codon located 100 codons downstream of the first ATG: alternative translation initiation produces a $135-\mathrm{kDa}$ protein ( 889 amino acids) that lacks the normal N-terminal domain [53]. Short and long FRQ (SFRQ, LFRQ) are required for optimal clock function [54]. LFRQ is the core of the circadian negative loop [55]. FRQ contains some important domains among its sequence [56] (Figure 2a).

After importation into the nucleus, FRQ homodimerizes via the N-terminal coiled coil domain and forms a functional homodimer [56]. LFRQ is also involved in temperature compensation of the clock [57,58]. Throughout this cycle, FRQ interacts with several proteins including FRH homologous to the yeast RNA-binding protein Dob1p/Mtr4p [59]. FRH associates with and stabilizes FRQ in an ATP-independent manner and it is essential for correct FRQ folding [60] (Figure 2b). In Neurospora the entire pool of FRQ is in complex with FRH; down regulation of frh expression abolishes circadian rhythmicity, resulting in high frq RNA levels. FRH binds the FRQ dimer in a stoichiometric manner to form a complex known as FCC; this complex acts as a part of the negative loop of the clock, inhibiting activity of the D-WCC and frq gene expression [61]. During this phase, FCC acts as a platform that recruits numerous kinases that will phosphorylate WCC and lead it to the degradation pathway (see Section 3.8). When FRQ levels drop below a certain threshold in the subjective late night, D-WCC is no longer inhibited by FRQ, and frq transcription is reactivated to start a new cycle [62]. Moreover, FRH acts non-enzymatically to support the intrinsically disordered FRQ [63]. This succession of positive and negative loops results in the circadian rhythmic oscillation of frq mRNA and protein, which is critical for the normal circadian behavior of an organism [64]. Moreover, FRH overexpression promotes WC-1 accumulation, confirming that FRH, together with FRQ, plays a role in stabilizing WC-1 [60]. Indeed, FRH-FRQ interaction is essential for maintaining correct WC protein levels in the positive feedback loops. Besides its role in repressing its transcription, FRQ also positively regulates 
the levels of both WC-1 and WC-2 through different mechanisms [65]. In the cytoplasm, FRQ acts as a positive factor by supporting WC-1 protein accumulation, leading to the formation of the WCC via an unknown mechanism [66]. The C-terminal part of FRQ is fundamental for its cytosolic localization [67]. This suggests that there are two different kinds of FRQ-mediated regulation of the circadian clock [68]. As said before, another light pulse can induce light-dependent frq mRNA to reset the clock when the frq level decreases. The Light/Dark transition is a highly reliable method for resetting circadian rhythm. Although the WCC/FRQ complex represents the core of the circadian system in Neurospora, other factors are also involved in this regulatory process.

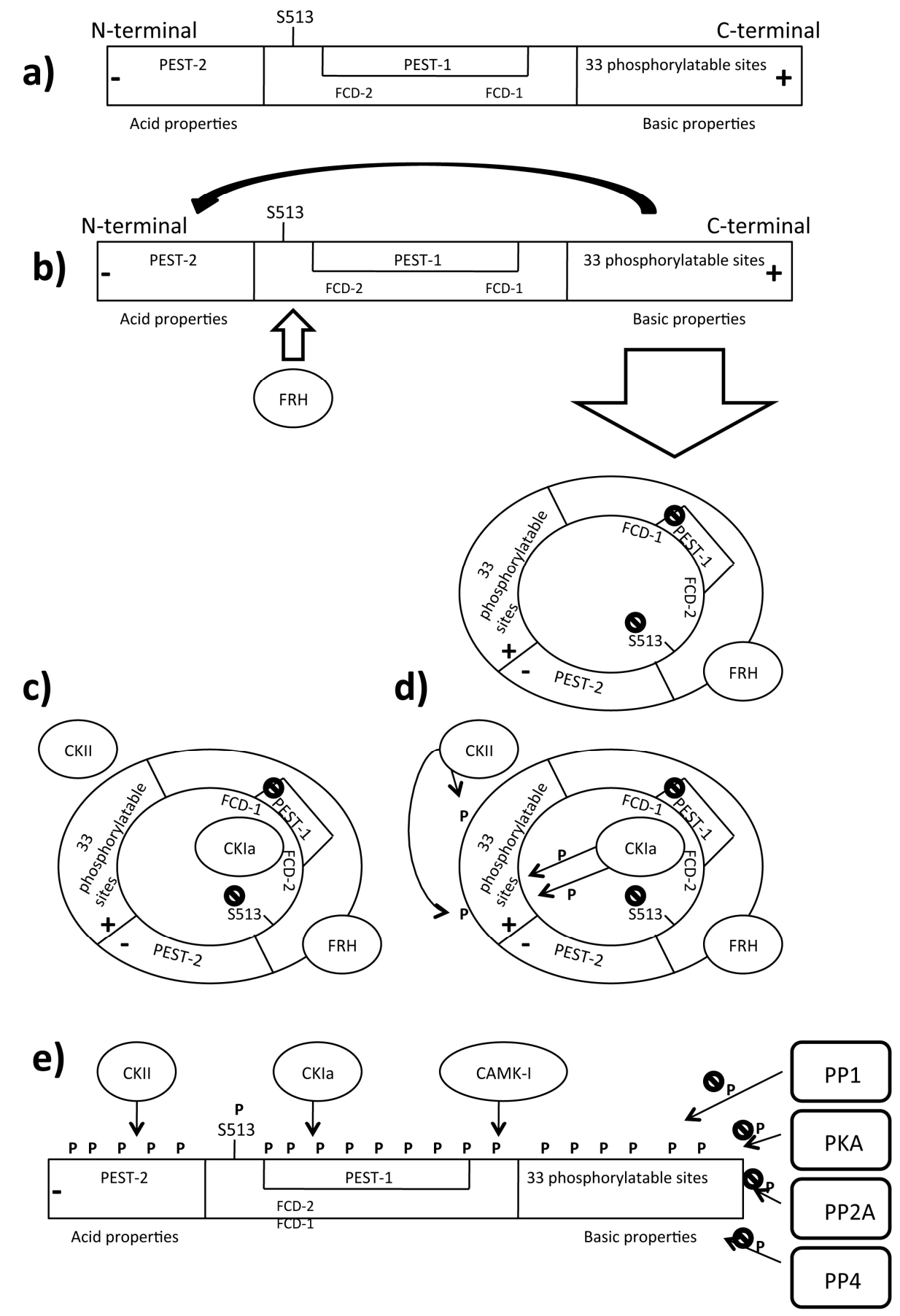

Figure 2. Phosphorylation related Frequency turnover. Legend: $\mathrm{CAMK}: \mathrm{Ca} / \mathrm{CaM}$ dependent kinase, CK: Casein kinase, E3: E3 ubiquitin ligase, FCD: Frequency/Casein kinase 
interaction domain, FRH: Frequency related helicase, FRQ: Frequency, FWD: F-box/WD40 repeat-containing protein, P: Phosphate group, PEST: P-E-S-T rich domain, PKA: Protein kinase A, PP: Protein phosphatase; (a) Domains that compose Frequency; (b) Newly synthesized FRQ recruits FRH that aids the correct fold of FRQ. The FRQ N-terminal domain interacts with the C-terminal domain, generating a closed structure that masks the PEST1 sequence and S513; (c) FRQ recruits the Casein kinase CKIa that binds the FCD sequences and physically interacts with FRQ. Other kinases such CKII are recruited on FRQ; (d) Casein kinases start to add phosphate groups to several FRQ domains; and (e) the addition of a negative phosphate groups abolishes the basic properties of the C-terminal domain, opening the closed structure. FRQ exposes its PEST sequences and the S513 residue that become targets of CKIa, CKII and CAMK1; at the same time many phosphatases contrast this activity, improving the FRA stability. When kinases' activity overcomes the phosphatases' activity, FRQ becomes highly phosphorylated and recruits FWD1 which is a substrate for E3 ubiquitinase (not shown in figure).

\section{Protein Posttranslational Modifications (PTMs) during the Circadian Clock, and Light Signal Transduction}

Posttranslational modifications (PTMs, e.g., phosphorylation and acetylation) alter protein behavior in response to conditional changes and regulate protein activity through different mechanisms, including protein-protein interactions, protein localization, degradation, and cleavage or allosteric regulation of enzyme activity [69-71]. They can activate or deactivate other regulators, thereby changing the PTM status of downstream proteins.

The basis of circadian rhythm generation is similar in all eukaryotes. The CLOCK/CYCLE heterodimer in Drosophila and CLOCK/BMAL1 in mammals are transcriptional activators, while PER/TIM in Drosophila and PER2/CRY in mammals are negative transcriptional factors [72]. Many PTMs regulate the activity of each circadian factor [73]. Phosphorylation is the most important PTM that regulates circadian rhythms [74]. The Drosophila double time (Dbt) gene, which encodes casein kinase 1 (CK1), was the first posttranslational modifier to be linked to the control of circadian rhythmicity by phosphorylating the Period (PER) transcription factor and influencing its own stability and subcellular localization [75]. DBT phosphorylates PER at several sites in a stepwise fashion and mediates its degradation by recruiting a conserved F-box/WD40-repeat protein (Slimb) [76]. This complex drives PER to the ubiquitin/proteasome pathway [77]. As described in Drosophila, PER2 in mammals is similarly regulated by phosphorylation [78]. Altered phosphorylation of human PER2 is responsible for the familial advanced sleep phase syndrome (FASP) caused by a mutation (S662G/) in the amino acid sequence [79]. Phosphorylation of the mammalian Clock, BMAL and the photoreceptor Cryptochrome 1 (CRY1) is widely described and associated with their stability and activity [80-85].

Acetylation, another important PTM in circadian and non-circadian systems, influences protein stability, protein-protein interactions, as well as translocation inside and outside the nucleus [86]. The transcriptional factor BMAL1 is acetylated by Clock and deacetylated by SIRT1 [87,88]. BMAL acetylation modifies its activity and ability to recruit the PER2/CRY heterodimer during the negative feedback loop in the mouse circadian rhythm [88]. Deacetylation of PER2 mediated by SIRT1 
promotes its degradation [89]. The components of the Neurospora circadian clock do not show strong structural homology with those of Drosophila, mammalian or human clocks, though they share many common functional features. Recent data suggest complex posttranslational regulation in the Neurospora clockwork through a molecular mechanism highly similar to higher eukaryotes. Here we outline the principal PTMs that regulate the non-histone proteins FRQ, WC-1 and WC-2 and similar modifications at level of chromatin.

\subsection{Faces and Timing of Frequency (FRQ) Phosphorylation}

FRQ is progressively phosphorylated during the day. Several evidences support that FRQ phosphorylation is related to its daily turnover $[52,90]$. First, in vivo phosphorylation is blocked after treatment with 6-DMAP, a general kinase inhibitor, and the total FRQ amount is increased, thus demonstrating the role of phosphorylation in FRQ stability [49]. Moreover, phosphorylation is essential for maintaining "in phase" the Neurospora circadian rhythm, as observed in strains treated with 6-DMAP in which circadian conidiation was aberrant [49]. Second, by systematic mutagenesis of the FRQ open reading frame (ORF), S513 has been identified among different putative phosphorylation sites as the most important. Elimination of S513 leads to a dramatic reduction in the rate of FRQ degradation and a significantly increased period caused by an increased stability of FRQ [49,91-96]. Third, over 75 sites have been identified by quantitative proteomics using nanoscale micro capillary liquid chromatography-mass spectrometry/mass spectrometry (LC-MS/MS or LC tandem MS) and analyzed by stable isotope labeling with amino acids in cell culture (SILAC) quantification [93]. These sites are mapped along the entire FRQ amino acid sequence. FRQ can be subdivided into three main regions: the acidic $C$-terminal domain, the central domain, and the $\mathrm{N}$-terminal domain that shows basic properties [94]. FRQ shows two PEST-like domains containing proline (P), glutamic acid (E), serine (S) and threonine (T) rich domain: PEST-1 in the central domain and PEST-2 in the N-terminal domain (Figure 2a). These domains are highly phosphorylated. Interestingly, deletion of the PEST-1 domain in FRQ results in an arrhythmic conidiation phenotype. Deletions of PEST-1 or mutations of S513 generate a very stable form of the FRQ protein, suggesting that loss of oscillating FRQ phosphorylation affects Neurospora circadian behavior. Deletion of PEST-2 does not reduce FRQ expression, but it is required for WC-1 stability. Some experimental evidence suggests that WC-1 accumulation is regulated by phosphorylation of FRQ at S513, S885, and S887. Mutation S885, 887 can affect the positive limb of the interconnected feedback loops, while deletion of the entire PEST-2 domain causes a more severe functional defect. PEST domain is involved in protein turnover in several organisms and seems to have the same function in FRQ [95]. The kinetics of FRQ oscillation is spatially and temporally coordinated by phosphorylation [96]. After the light/dark shift that leads Neurospora circadian entrainment (time point 0), a high amount of FRQ is hypophosphorylated in constant darkness (DD) up to $14 \mathrm{~h}$ after light synchronization (DD14, corresponding to subjective morning). A low amount of FRQ protein is highly phosphorylated $24 \mathrm{~h}$ after light synchronization (DD24, corresponding to subjective night). This means that at DD14 the total amount of FRQ is higher than the total amount at DD24, suggesting that phosphorylation is associated with the degradation pathway [23]. Newly synthesized hypophosphorylated FRQ contains a nuclear localization signal (NLS) and is trapped in the nucleus more efficiently than hyperphosphorylated species $[56,66]$. 
Despite the presence of a NLS, only a small fraction of FRQ is localized in the nucleus and the majority of the protein accumulates in the cytosol [23,96]. FRQ phosphorylation inhibits nuclear import, and retains the proteins in the cytoplasm where it acts as a positive factor by supporting the WC-1 protein accumulation, as said before. Since phosphorylated FRQ exert diverse functions such as support of WCC accumulation in the cytosol and inactivation of WCC activity into the nucleus, it indirectly influences the daily oscillation of hundreds of genes that are under the control of the WCC as well.

Recent observations provided evidence that FRH is critical for the maintenance of FRQ phosphorylation profile and stability [67]. Loss of FRQ-FRH interactions, or down-regulation of FRH, promotes the hypophosphorylated form of the FRQ:FRQ altering the normal circadian pathway [97]. Many kinases are involved in FRQ regulation. In the following paragraph, we will describe the principal kinases involved in the full length FRQ phosphorylation.

\subsection{Kinases Targeting FRQ}

\subsubsection{CKIa and CKIb}

Two putative kinases involved in FRQ phosphorylation are CKIa and CKIb, which are homologous to human kinase 1 epsilon [98,99]. CKIa co-immunoprecipitates with FRQ in both dark and light conditions, suggesting that it is a member of the FRQ complex throughout the entire circadian cycle. It shows a substantial preference for the highly phosphorylated FRQ form [48]. Prevention of the interaction between FRQ and CKIa leads to a hypophosphorylated state of FRQ. FRQ is hypophosphorylated and shows slow degradation in the $C K I a^{\mathrm{L}}$ mutant strain in which the activity of CKIa is abolished, confirming that FRQ is a target of CKIa in vivo. Finally, the progression timing of FRQ phosphorylation is delayed in this mutant [98].

FRH is also known to associate with FRQ, stabilizing it in an ATP-independent manner. The ATPase of FRH attenuates the kinetics of CKIa-dependent hyperphosphorylation of FRQ, suggesting that phosphorylation regulates the entire FCC complex [100]. CKIa interacts with FRQ by two sequences, called FCD2 (aa 488 to aa 495) and FCD1 (162 amino acids downstream of FCD2) located in the central domain of FRQ named FCD. The FCD region (aa 470 to aa 532) also includes the PEST-1 domain. Deletion of one of the FCD domains totally abolishes CKIa binding on FRQ, indicating that a high-phosphorylated form of FRQ is necessary for its binding [48,98]. In vitro experiments demonstrated that both $\mathrm{CKIa} / \mathrm{CKIb}$ target PEST-2; however, tandem MS analyses were unable to recognize highly phosphorylated sites within this region. Only CKIa targets PEST-1. The FRQ N-terminal domain contains 33 residues that can be phosphorylated by various kinases. In particular, CKIa and $\mathrm{CKIb}$ have been suggested for this role, though $\mathrm{CKIb}$ is onlyable to phosphorylate the N-terminal domain in vitro [101]. Figure 2c-e shows where CKIa is mapped along FRQ sequence.

\subsubsection{CKII}

Another kinase, the Neurospora casein kinase II (CKII), was isolated and characterized starting from camk-1 mutant complementation [102,103]. CKII is a holoenzyme composed of three subunits: $\mathrm{CKA}, \mathrm{CKB} 1$, and CKB2. CKA is the catalytic subunit; CKB1 and CKB2 are the regulatory elements. 
Phosphorylation of FRQ by CKII is important in regulating the stability of FRQ. The FRQ phosphorylation pattern was significantly altered in $c k a^{R I P}$ mutants in DD and LL phases and the levels of FRQ were higher in the mutants than in the wild-type strains. Slower FRQ degradation was observed in the Light/Dark transition. In the $N$. crassa wild-type strain, FRQ was rapidly degraded after the Light Dark (LD) with 40\% FRQ left after $8 \mathrm{~h}$ in the dark. In contrast, FRQ degradation rate was significantly slower in a $c k a^{R I P}$ strain after the LD transition (80\%) of FRQ was still present in the mutant after $8 \mathrm{~h}$ in the dark). Again, the increased amount of FRQ found in the mutant is consistent with the fact that phosphorylation of FRQ triggers its own degradation [49]. Phosphorylation of FRQ by CKII plays important roles in regulating the formation of the FRQ:WC complex and the closing the circadian negative feedback loop. FRQ nuclear localization was unchanged in $c k a^{R I P}$ mutant strains but CoIP assay demonstrated that a large amount of FRQ coprecipitated with WC-1 in the mutant strain, suggesting that the hypophosphorylated FRQ in the $c k a^{R I P}$ mutant stabilizes and promotes the formation of the FRQ:WC complex. These data indicate that phosphorylation of FRQ by CKII decreases FRQ's ability to interact with the WC proteins. The circadian negative feedback loop was impaired in the CKII mutant and FRQ failed to inhibit the transcriptional activation activity of the WC complex effectively in the CKII mutant even if it strongly interacts with WCC. This means that although the interaction between FRQ and the WCs is necessary for the closing of the circadian negative feedback loop the interaction alone is not sufficient for FRQ to act to repress the transcriptional activation of frq by the WC proteins $[65,104]$. The molecular phenotypes of CKII mutants are very similar to those of the frq null strain. We can conclude that Neurospora CKII is an important component of the Neurospora circadian system. Figure 2c-e shows where CKII is mapped along FRQ sequence.

\subsubsection{CAMK1}

Nakashima and colleagues have shown that the circadian and light dependent conidiation rhythm of Neurospora can be phase-shifted by CaM antagonists $[105,106]$. This finding and the identification of a $50 \mathrm{kDA} \mathrm{Ca} / \mathrm{CaM}$-dependent kinase CAMK1 as one of the kinases targeting FRQ [91] suggested the involvement of CaM kinase in FRQ activity. It is very similar to other eukaryotic $\mathrm{Ca} / \mathrm{CaM}$-dependent kinases, with a highly conserved catalytic domain. In vivo and in vitro assays have demonstrated that CAMK1 is responsible for FRQ phosphorylation. The phosphorylation activity requires both $\mathrm{Ca}^{2+}$ and CaM. A chelator of $\mathrm{Ca}^{2+}$ can also inhibit the phosphorylation of the endogenous FRQ in Neurospora extracts. CAMK-1 accounts for near half of the FRQ phosphorylation, including the region aa 501-519, which contains the three known functionally important phosphorylation sites (T501, S513, S519). The circadian clock is affected in the camk-1 KO mutant, in which the running phase of conidiation showed a modest delay as compared with the wild-type strain. The phenotypes of the camk-1 null strain suggest that it plays an important role in growth and development. The phase response to light was also altered in the camk-1 mutant. All together these data evidenced the importance of the FRQ phosphorylation in the regulation of the Neurospora circadian clock and light signal transduction. The mild clock phenotype and the significant FRQ kinase activity in the camk-1 KO strains suggested that FRQ might be phosphorylated also by other kinases. Figure 2e shows where CAMK is mapped along FRQ sequence. 


\subsection{FRQ Stabilization}

\subsubsection{PKA}

Unlike the kinases previously described, which promote FRQ degradation, protein kinase a 1 (PKA) stabilizes FRQ protein [107] (Figure 2e). In strains with high PKA activity, like $m c b$ strains, frq mRNA levels are extremely low, but FRQ protein is at an intermediate level of abundance in DD and it is more stable than in the wt strain. In addition, FRQ is hypophosphorylated in DD in the pkac-1 KO strains [107]. These data reveal that the PKA-mediated FRQ phosphorylation in Neurospora has effects similar to hPER2 phosphorylation at the FASPS sites in humans [108,109]. The Neurospora PKA can directly phosphorylate FRQ in vitro and FRQ phosphorylation mediated by PKA stabilizes the protein but PKA does not associate tightly with FRQ and the mechanism is still unclear to date.

How does PKA-mediated phosphorylation of FRQ inhibits FRQ own degradation pathway? It has been proposed that this phosphorylation probably either alters the FRQ structure conformation or inhibits its phosphorylation by CK-1a and CKII in a way that it cannot be efficiently ubiquitinated and degraded. A fairly similar mechanism was observed in mammals. In the mammalian WNT signaling pathway, for example, phosphorylation of $\beta$-catenin by PKA is known to inhibit the ubiquitination of $\beta$-catenin promoted by CKI and glycogen Synthetase kinase $3 \beta$ (GSK-3 $\beta$ ) phosphorylation [110,111].

\subsubsection{PP1, PP2 and PP4}

A dephosphorylating pathway that can counteract the increasing phosphorylating level of FRQ requires phosphatase enzymes. PP1 and PP2a were identified in N. crassa and suggested as regulators of the Neurospora circadian clock [112]. The ppp- $1^{R I P}$ mutant affects FRQ dephosphorylation, compromising the protein's normal degradation rate, which is faster than in the wild type and it also affects Neurospora circadian entrainment. Disruption of the catalytic subunit RGB-1 of PP2a ( $r g b-1^{R I P}$ mutant) affects the normal phosphorylation cycle and normal circadian conidiation in $N$. crassa as well. This suggests that FRQ is an in vivo target of PP1 and PP2a, even though only PP1 is really able to affect FRQ protein stability. Low FRQ protein and frq mRNA levels were observed in the $r g b-l^{R I P}$ strain, differently from what was observed in the CKII mutant, suggesting that PP2A activity counteracts CKII activity and probably prevents closing of the negative feedback loop (Figure 2e).

Another phosphatase identified in N. crassa is PP4 (Figure 2e), a homolog of the human catalytic subunit of protein phosphatase 4 [113,114]. Mutant strains that abolished PP4 activity showed a deregulation of circadian rhythm period and amplitude. PP4 physically interacts with FRQ, which is hyperphosphorylated and increases its degradation rate in a pp4 KO strain. These data suggest that PP1 and PP2a and PP4 all antagonize the effects of the kinases and stabilize FRQ protein. Table 1 lists the proteins implicated in FRQ turnover. 
Table 1. Proteins interacting with FRQ.

\begin{tabular}{|c|c|c|c|c|}
\hline Protein & Target & Activity & Effects & Other Information \\
\hline \multirow{3}{*}{ FRH } & \multirow{2}{*}{ FRQ } & \multirow{2}{*}{ Promotes FRQ conformational changes } & Ensures proper folding of FRQ & \multirow{3}{*}{ NA } \\
\hline & & & Masks some residues to CKIa phosphorylation & \\
\hline & frq mRNA & FRH physically interacts with frq mRNA & Exosomal degradation of mRNA & \\
\hline \multirow{5}{*}{ CKIa } & FRQ N-terminal domain & Phosphorylation & Conformational changes & Recruited on FRQ FCD domains \\
\hline & FRQ PEST-1 domain & Phosphorylation & FWD-1 recruitment & NA \\
\hline & FRQ S513 & Phosphorylation & FWD-1 recruitment & NA \\
\hline & FRQ N-terminal domain & Phosphorylation & FWD-1 recruitment & NA \\
\hline & FRQ Central domain & Phosphorylation & FWD-1 recruitment & NA \\
\hline \multirow{5}{*}{ CKII } & FRQ N-terminal domain & Phosphorylation & Conformational changes & Recruited on FRQ FCD domains \\
\hline & FRQ PEST-1 domain & Phosphorylation & FWD-1 recruitment & NA \\
\hline & FRQ S513 & Phosphorylation & FWD-1 recruitment & NA \\
\hline & FRQ N-terminal domain & Phosphorylation & FWD-1 recruitment & NA \\
\hline & FRQ Central domain & Phosphorylation & FWD-1 recruitment & NA \\
\hline \multirow{4}{*}{ CAMK-1 } & FRQ N-terminal domain & Phosphorylation & FWD-1 recruitment & NA \\
\hline & FRQ PEST-1 domain & Phosphorylation & FWD-1 recruitment & NA \\
\hline & FRQ S513 & Phosphorylation & FWD-1 recruitment & NA \\
\hline & FRQ N-terminal domain & Phosphorylation & FWD-1 recruitment & NA \\
\hline $\mathrm{CKIb}$ & FRQ N-terminal domain & Phosphorylation & Conformational changes & $\begin{array}{c}\text { Interaction with } \mathrm{N} \text {-terminal domain } \\
\text { demonstrated only in vitro }\end{array}$ \\
\hline
\end{tabular}


Table 1. Cont.

\begin{tabular}{|c|c|c|c|c|}
\hline Protein & Target & Activity & Effects & Other Information \\
\hline \multirow{4}{*}{ PP1 } & FRQ PEST-1 domain & Dephosphorylation & Contrasting phosphatase action-FRQ stabilization & NA \\
\hline & FRQ S513 & Dephosphorylation & Contrasting phosphatase action-FRQ stabilization & NA \\
\hline & FRQ N-terminal domain & Dephosphorylation & Contrasting phosphatase action-FRQ stabilization & NA \\
\hline & FRQ Central domain & Dephosphorylation & Contrasting phosphatase action-FRQ stabilization & NA \\
\hline \multirow{4}{*}{$\mathrm{PP} 2 \mathrm{~A}$} & FRQ PEST-1 domain & Dephosphorylation & Contrasting phosphatase action-FRQ stabilization & NA \\
\hline & FRQ S513 & Dephosphorylation & Contrasting phosphatase action-FRQ stabilization & NA \\
\hline & FRQ N-terminal domain & Dephosphorylation & Contrasting phosphatase action-FRQ stabilization & NA \\
\hline & FRQ Central domain & Dephosphorylation & Contrasting phosphatase action-FRQ stabilization & NA \\
\hline \multirow{4}{*}{ PP4 } & FRQ PEST-1 domain & Dephosphorylation & Contrasting phosphatase action-FRQ stabilization & NA \\
\hline & FRQ S513 & Dephosphorylation & Contrasting phosphatase action-FRQ stabilization & NA \\
\hline & FRQ N-terminal domain & Dephosphorylation & Contrasting phosphatase action-FRQ stabilization & NA \\
\hline & FRQ Central domain & Dephosphorylation & Contrasting phosphatase action-FRQ stabilization & NA \\
\hline FWD-1 & Hyperphosphorylated FRQ & Physical interaction with FRQ & SCF-type ubiquitin E3 ligase recruitment & NA \\
\hline $\begin{array}{c}\text { SCF-type ubiquitin } \\
\text { E3 ligase }\end{array}$ & Hyperphosphorylated FRQ & Ubiquitination of FRQ & FRQ proteasomal degradation & NA \\
\hline
\end{tabular}




\subsection{Molecular Mechanisms of FRQ Phosphorylation and Proteasomal Degradation}

Actually there are described at least 113 phosphorylated sites identified in FRQ [93,101]. MS analyses showed that the full-length FRQ phosphorylation is favored when FRQ is preliminarily phosphorylated in some specific sites, suggesting that it is regulated by a specific mechanism for phosphorylation. One explanation of this process is that newly synthesized, hypophosphorylated FRQ adopts preferentially the closed conformation supported by electrostatic interactions of the positively charged N-terminal domain with the negatively charged remainder portion of the protein [115]. Early phosphorylation of some sites in the C-Term region and middle portion could assist to strengthen the closed state that allows stabilization of FRQ.

Subsequently CKIa and CKII start to phosphorylate the N-terminal of FRQ, masking the basical properties of the $\mathrm{N}$-terminal domain. As a result, $\mathrm{N}$-terminal domain can no longer interact with the C-terminal acid domain. This event causes a conformational change in FRQ that exposes the S513 and the PEST-1 sequence of the central domain. Then CKIa, CKII, and CAMK-1 phosphorylate the PEST sequences, the S513 residue, and many other residues dislocated along the entire protein, except for the C-terminal domain, which is never phosphorylated. This means that the circadian oscillation of FRQ phosphorylation is due to multiple reactions throughout the FRQ structure and in the spatial and temporal combination of these kinases [116]. The FRQ phosphorylation pathway is illustrated in Figure 2. The combination of these phosphorylation processes leads FRQ to the degradation pathway. Some findings indicate that hyperphosphorylated FRQ is degraded by proteasome. First, ophiobolin A, a well-known calmoduline inhibitor tested to identify CAMK involvement in FRQ phosphorylation, promotes protein ubiquitination and the formation of higher molecular weight conjugates of FRQ in vivo [117]; Second, disruption of the $f w d l$ gene (homolog of the Drosophila Slimb protein), which encodes a protein containing F-box and VD4causes hyperphosphorylation of FRQ with a pattern different from that observed in wild-type strains [118]. FWD, a member of the SCF-type ubiquitin ligase complex, seems to directly ubiquinate FRQ. Hence, FWD mutation decreases the FRQ degradation rate because the protein appears to be more stable than in the wild-type strain; Third, the accumulation of FRQ in the $f w d-1$ mutant strain is associated with dysfunctions in circadian oscillation though the Dark/Light transition still occurs; Fourth, FRQ physically interacts with FWD-1 in vivo, driving FRQ to the degradation pathway, as observed in the fwd-1 mutant that was still able to bind FRQ but lacked the F-box domain involved in FRQ degradation. In summary, these data indicate that FRQ phosphorylation promotes FRQ degradation through the ubiquitin-proteasome pathway mediated by ubiquitin E3 ligase (Figure $2 \mathrm{f}$ ).

\subsection{White Collar Complex (WCC) Light Dependent Phosphorylation}

Evidence suggests that the light-dependent WCC pathway is influenced by protein phosphorylation $[119,120]$. It has been demonstrated that WC-1 becomes highly phosphorylated 15 min after multiple light pulses and that the phosphorylation level decreases to the same levels as in dark after $2 \mathrm{~h}[121,122]$. Functional WC-2 is not required for PTM of WC-1 but it could influence the degree of PTM and the stability of WC-1. Light-dependent WC-1 phosphorylation oscillation correlates with the expression of light-dependent gene (e.g., al-3). As observed for FRQ, WC-1 
phosphorylation is also coupled with its own degradation. Pharmacological studies and in vitro phosphorylation assays have suggested that protein kinase $\mathrm{C}$ (PKC) may phosphorylate WC-1 [123] (Figure 3a-2).

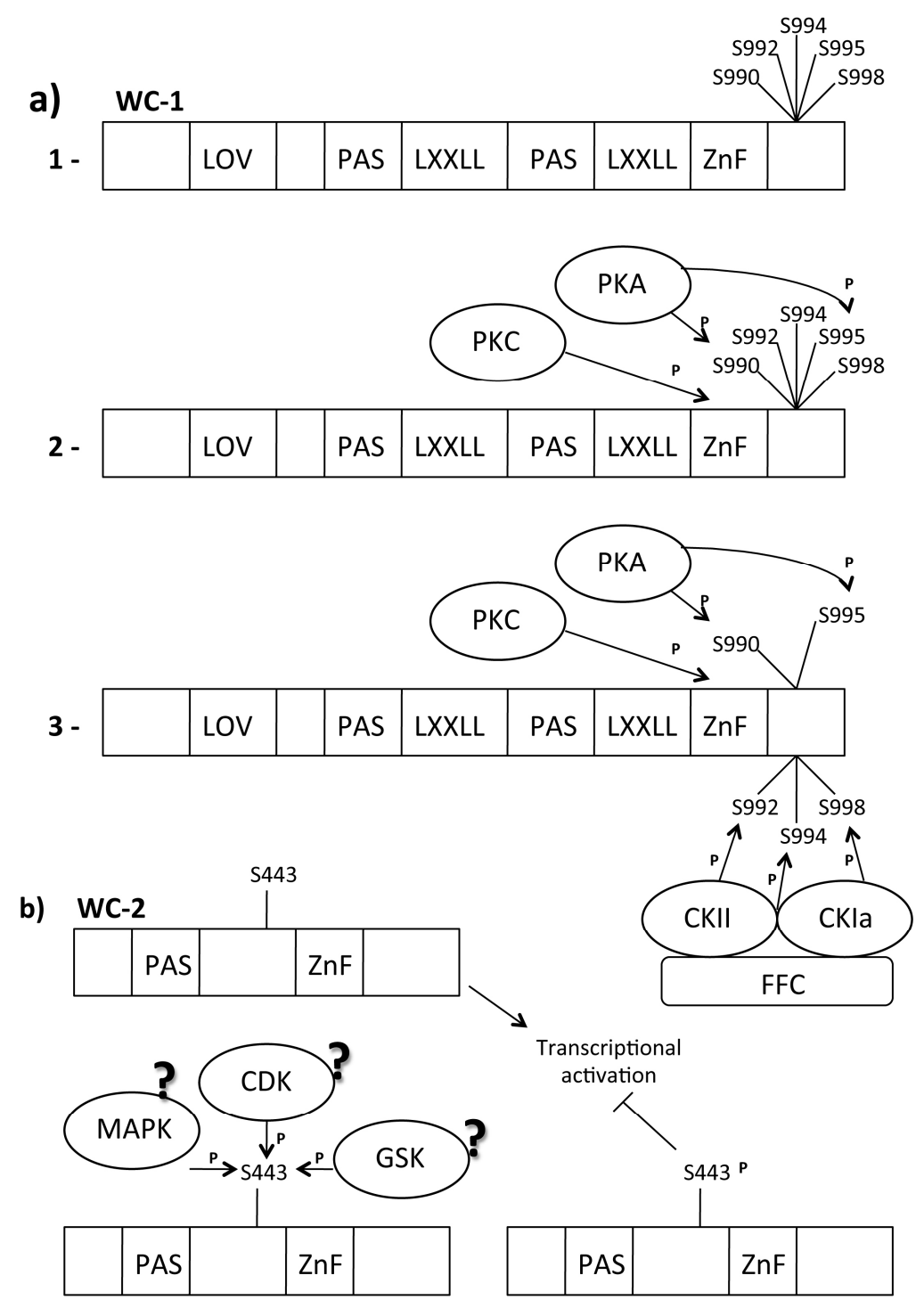

Figure 3. WC-1/WC-2 post translation modification (PTM) Modifications. Legend: ?: Supposed, CDK: Cyclin dependent kinase, CK: Casein kinase, FRQ: Frequency, GSK: Glycogen Synthetase kinase, LXXLL: WC-1/NGF1 interaction domains, LOV domain: Light-Oxygen-Voltage domain, MAPK: MAP activated protein kinase, P: Phosphate group, PAS domain: Per Arnt Sim domain, dimerization domain, PKA: Protein kinase, AS443: Phosphorylatable Serine residue, S990-992-994-995-998: Phosphorylatable Serine residues, Zn finger: Zinc finger, WC-1/DNA binding domain. (a): (1) Important WC1 domains; (2) PKA is an FRQ-independent kinase that phosphorylates the WC-1 S990 and S995; (3) Phosphorylation of S990 and S995 is a signal for CKII and CKIa (kinase recruited by FRQ) to phosphorylate S992, S994 and S998. This phosphorylation destabilizes WC-1, generating a transcriptional repression of light-activated genes; (b) TheWC2 active state is non-phosphorylated. When S433 became phosphorylated the WCC activity results reduced. 
In vivo and in vitro experiments have confirmed that $\mathrm{PKC}$ regulates light responses affecting light-dependent WC-1 protein stability $[124,125]$. PKC seems to be able to phosphorylate the WC-1 zinc-finger domain. The zinc-finger domain is important for the function of WC-1 in the dark [26]. PKC physically interacts with WC-1 in dark conditions, but this interaction is no longer detectable after $30 \mathrm{~min}$ of light exposure when WC-1 is hyperphosphorylated. This suggests that light-mediated WC-1 hyperphosphorylation affects PKC/WC-1 interaction. Phosphorylation of WC-2 appears to be more stable over time after light exposure [122] and shows strong oscillation when analyzed by two-dimensional electrophoresis [126]. The cytoplasmic WC-2 protein is not modified in response to light, suggesting that light-specific phosphorylation is limited to nuclear pool of WC-2 [122]. Finally, it has been demonstrated that WC-2 light-specific phosphorylation depends on a functional WC-1. The translocation of WC-1 and WC-2 into the nucleus is independent of light-specific phosphorylation, unlike that observed for FRQ phosphorylation [23]. MS analyses identified S443 as the phosphorylation target in WC-2 protein [127] (Figure 3b).

S433 plays a role in the regulation of WCC activity but it does not affect WCC turnover according to mutagenesis experiments. The activity and the stability of WCC were increased and the timing of photoadaptation was anticipated (probably due to more rapid accumulation of the blue-light photoreceptor VVD) in the $s 433 a$ strain, a WC-2 variant in which $\mathrm{S} 443$ is mutated in A, thus preventing WC-2 phosphorylation. In contrast, WCC was less active in the $s 433 d$ strain in which mutation of Sto Emimics the phosphorylated state of WC-2. The phosphorylation site S433 is located directly upstream of a prolyl residue, suggesting that it could be target of serine/threonine kinases such as MAPK-activated protein kinase (MAPK) and Cyclin-Dependent Kinase (CDK) [128]. Table 2 lists the kinases that target the White Collar Complex.

Table 2. Kinases targeting the White Collar Complex.

\begin{tabular}{|c|c|c|c|c|c|c|}
\hline $\begin{array}{c}\text { Protein } \\
\text { Name }\end{array}$ & $\begin{array}{r}\text { Protein } \\
\text { Target } \\
\end{array}$ & $\begin{array}{c}\text { AA } \\
\text { Target }\end{array}$ & Activity & Effects & Other Information & Other Information \\
\hline PKA & WC-1 & $\begin{array}{l}\text { S990 } \\
\text { S995 } \\
\end{array}$ & Phosphorylation & $\begin{array}{l}\text { Inhibition WCC activity } \\
\text { Putative Priming kinase }\end{array}$ & $\begin{array}{l}\text { FRQ independent } \\
\text { kinase } \\
\end{array}$ & $\begin{array}{c}\text { Interaction } \\
\text { experimentally proven }\end{array}$ \\
\hline $\mathrm{PKC}$ & WC-1 & $\begin{array}{c}\mathrm{Zn} \\
\text { Finger }\end{array}$ & Phosphorylation & Decreased WC-1 stability & NA & $\begin{array}{c}\text { Interaction } \\
\text { experimentally proven }\end{array}$ \\
\hline CKIa & WC-1 & $\begin{array}{l}\text { S992 } \\
\text { S994 } \\
\text { S998 }\end{array}$ & Phosphorylation & Decreased WC-1 activity & $\begin{array}{c}\text { Kinases recruited } \\
\text { by FRQ }\end{array}$ & $\begin{array}{c}\text { Interaction } \\
\text { experimentally proven }\end{array}$ \\
\hline CKII & WC-1 & $\begin{array}{l}\text { S992 } \\
\text { S994 } \\
\text { S998 } \\
\end{array}$ & Phosphorylation & Decreased WC-1 activity & $\begin{array}{c}\text { Kinases recruited } \\
\text { by FRQ }\end{array}$ & $\begin{array}{c}\text { Interaction } \\
\text { experimentally proven }\end{array}$ \\
\hline GSK & WC-1 & & Phosphorylation & & NA & $\begin{array}{c}\text { Interaction } \\
\text { experimentally proven }\end{array}$ \\
\hline Unknown & WC-2 & S443 & Phosphorylation & Decreased WCC activity & NA & NA \\
\hline
\end{tabular}

\subsection{White Collar 1 (WC-1) Light Dependent Acetylation}

Recent evidence suggests that $\mathrm{WC}-1$ can be acetylated in vitro and in vivo along the entire sequence [129]. Though the role of WC-1 acetylation is not clear, this PTM seems respond to light 
signals. Neurospora Gen Five-1, (the histone acetyl transferase homologous to the Yeast Gen5p and Human GCN5) could be involved in acetylation of WC-1 as well as histone H3 of light induced gene promoters [130]. However, analysis of the $n f g l^{R I P}$ mutant did not confirm this hypothesis because WC-1 was still acetylated in this mutant strain.

\subsection{The FRQ-Independent WCC Circadian Phosphorylation}

MS/MS analyses identified five phosphorylated Sin WC-1 (S990, S992, S994, S995, S998), which are phosphorylated in vivo and localize in a region immediately downstream of the zinc-finger domain [131] (Figure 3a-1). Biochemical analyses have demonstrated that these five phosphorylation sites are not involved in the light-induced hyperphosphorylation of WC-1. However, phosphorylation of these sites appears to be necessary for maintaining WC-1 steady state levels, as observed in strains in which these serine were mutated. Mutations at these sites affect normal circadian oscillation in $N$. crassa though they do not affect light-dependent responses. They might be involved in the positive limb of the circadian negative feedback loop [111]. The amount of WC-1 was found to determine the expression of frq in the dark in a wild-type strain; in the mutant with all five sites mutated, the frq mRNA level was slightly higher, suggesting that these phosphorylation events negatively regulate the transcriptional activation of WC-1 in the dark. S990 was the first of the five phosphorylated Serine mentioned above to be phosphorylated. Several experiments indicate protein kinase A (PKA) for this role (Figure 3a-1): both WC proteins are hypophosphorylated in the $p k a^{C}$ mutant strain, they physically interact with PKA and are phosphorylated by this kinase; PKA associates with WCC but not with FRQ, suggesting that phosphorylation of WCs by PKA is independent of FRQ; in vivo experiments demonstrated that PKC phosphorylates WC-1 in the region near the DNA binding domain and that this phosphorylation stabilizes the WC-1 protein; phosphorylation of WCs by PKA strongly inhibits WCC activity, resulting in the inhibition of $f r q$ transcription. Phosphorylation occurs upstream from CK-1a and CKII during WCC inhibition. Finally, PKA and its regulatory subunit PKAR are essential for normal circadian rhythm because WC-1 is less stable in a PKA mutant strain and the circadian transcription of clock-controlled genes is compromised. These data suggest that PKA can act as a priming kinase on WC-1. Bioinformatics analyses have shown that the sequence context around residues 990 (KSNSP) might be a direct target of PKA, whereas S995 (SHSSP) is not a typical PKA site (R-X-S/T or R-R/K-X-S) [132].

The FRQ-independent phosphorylation of S990 and S995 can convert the other sites into CKIa and CKII targets [107]. Phosphorylation of S990 significantly enhanced the ability of CK-1a to phosphorylate this region. This means that phosphorylation of S990 mediates the recruitment of the other kinases and that the subsequent phosphorylation events are mediated by a priming kinase. Recently, GSK entered in the group of the circadian clock regulators of $N$. crassa; GSK physically interacts with the WCC, phosphorylating both subunits with high specificity in a complex protein environment in vitro [133]. GSK also influences WC-1 protein stability, as observed in strains in which GSK (Glycogen Synthetase Kinase) activity was reduced, and it was coupled with an increased amount of WC-1. Since GSK affects the free-running period of Neurospora, the kinase must act on the dark form of the WCC. 


\subsection{The FRQ-Dependent WCC Circadian Phosphorylation}

In the nucleus, the WCC is present in excess over FRQ. Consequently, FRQ can neutralize only a very small fraction of WCC by binding stoichiometrically the complex and by regulating WCC phosphorylation [126]. An analysis carried out in different $f r q$ mutants $\left(f r q^{10}, f r q^{9}\right)$ showed the typical loss of electrophoretic mobility of phosphorylated proteins for WC-1 and WC-2. Since the frq $q^{9}$ mutant produces a truncated FRQ protein lacking the $\mathrm{C}$-terminal domain, this domain seems to be essential for WC-1 phosphorylation, as well as for shuttling of FRQ into the nucleus. FRQ-dependent phosphorylation leads to WCC inactivation [62]. This means that the phosphorylation level of the WCC during the circadian cycle correlates with the function of WCC as a transcription activator. Hypophosphorylated WCC efficiently binds the C-box of frq promoter, while hyperphosphorylated WCC binds the C-box with reduced affinity and does not efficiently activate the transcription of target genes.

How does FRQ influence WCC phosphorylation during daily circadian oscillation? FRQ physically interacts with CKIa and it is cyclically phosphorylated by this kinase (Figure 2c,d). It also forms a complex with WCC in the nucleus, suggesting that WCC could be target of CKIa. Immunoprecipitation experiments demonstrated the physical interaction between WC-1 and CKIa and this binding is FRQ-mediated. Disruption of the interaction between FRQ and CKIa also affects the binding between WC-1 and CKIa [98]. Functional mutation of CKIa ( $c k-1 a^{\mathrm{L}}$ strain) confirmed the involvement of this kinase in WCC phosphorylation.

FRQ/CKIa interaction is regulated by FRH [106] (Figure 2b,c); FRH with FRQ forms the FFC complex, which inhibits WCC activity [100]. This means that FRH is also important for WCC circadian phosphorylation. Moreover, WCC is also phosphorylated by CKII [98]. These results suggest that FRQ acts as a kinase substrate-recruiting subunit to mediate the phosphorylation of WCC by recruitment of CKIa and CKII. In turn, WCC phosphorylation affects its ability to be recruited at the C-box and LRE elements of the promoter sequences of regulated genes. WC-1 rhythmically binds the frq $\mathrm{C}$-box, but this binding is enhanced in the $c k-1 a^{\mathrm{L}}$ strain, confirming that a hypophosphorylated form of the WCC is required for its transcriptional activity [98].

The daily increase in WC-1 protein abundance seems to be correlated with the hyperphosphorylated form of FRQ. Accumulating data suggest that FRQ modulates the stability of total WC-1 protein, promoting its own accumulation and turnover [68]. Physical interaction between FRQ and WC-1 is essential for this process, and it has been suggested that FRQ-dependent clearance of WC-1 from the nucleus is a closure mechanism of the negative feedback loop mediated by oscillation in the FRQ: WCC ratio [134]. Translocated WC-1 can be reactivated in the cytoplasm in an FRQ-mediated manner $[23,66]$. Though it is not clear how FRQ can reactivate WC-1, it probably mediates the formation of the WCC.

\section{Chromatin Epigenetic Modifications Involved in Circadian Rhythms and Light Signal Transduction}

Chromatin is a not a simple packaging system of eukaryotic DNA but a more or less condensed nucleo-protein structure, modulated in time and space and associated with on/off states of transcriptional activity. In fact, condensed chromatin presents an obstacle for the double helix binding 
of transcription factors, resulting in a general inhibition of gene expression [135,136]. Chromatin consists of positively charged tails of histone proteins interacting with the negatively charged DNA phosphate backbone. Chromatin remodeling derives from the activity of histone modifiers affecting histone-DNA interaction by altering the charge of the histone tail [137] or/and from the activity of enzymes altering the DNA topology.

The modifiers can methylate, acetylate or phosphorylate histones, and the combination of these modifications is coupled with the state of chromatin [138,139]. Transcriptional activation is generally preceded or accompanied by local remodeling of chromatin structure. Since the histone tail alters the nucleosome structure via a number of active and inactive histone marks, inducing either a condensed silenced state or a decondensed active state of chromatin, the term "histone code" was coined to describe this process [140].

In mammals and plants, rhythmic changes in chromatin structure have been correlated with changes in the transcriptional activity of clock-associated loci and light responses. In mammals, acetylation of histone $\mathrm{H} 3$ at Per1, Per2, and Cry (genes encoding negative transcription factors involved in the mammal circadian clock) and acetylation of $\mathrm{H} 4$ at Perl coincide with the peak during the transcriptional activation phase [141]. In contrast, histone H3 associated with Per1 and Per 2 becomes methylated at K27 or K79 during the repressive phase [142,143]. A transient burst of histone H3 phosphorylation on residue S10 (H3S10) has been observed in mammalian hypothalamic suprachiasmatic nuclei following multiple light pulses [144]. Recently, mixed-lineage leukemia (MLL1) lysine methyltransferase (KMT2A) has been shown to associate with the circadian core CLOCK-BMAL and is required for the rhythmic expression of clock genes [145]. In mammals and plants, Jumonji domain-containing protein 5 (JMJD5) lysine dimethyltransferase (KDM8) is rhythmically expressed and is required for normal circadian rhythms [146,147]. In plants, the circadian clock regulates the pattern of H3 acetylation of the Timing of Cab 1 gene (TOC1) promoter. The rhythmic oscillation of $\mathrm{H} 3$ acetylation, as well as binding of chromatin remodeling factors, closely follows the circadian expression of the TOC1 gene mediated by circadian clock associated 1 (CCA1) [148]. Collectively, these and other data strongly suggest a conserved interspecies molecular mechanism that couples light signal transduction and circadian rhythms with chromatin remodeling. Here we give a general overview of PTMs involved in the modulation of chromatin structure of circadian and light-dependent genes in the WCC model system, which may be considered as functional ancestor of the core clock system in mammals, plants and flies.

\subsection{Chromatin Acetylation}

Specific interactions between light-responsive regions (LRR) of the light-dependent genes and WCC have been demonstrated in vivo [27]. In vitro DNA binding assays using recombinant zinc-finger domains of WC-1, NIT-2, and CYS-4 did not preferentially bind to their specific GATA repeats on naked DNA segments consisting of target promoters [149]. This suggested the existence of other not yet described factors necessary in this interaction might be important in conferring specificity to the response. The correlation between chromatin remodeling and light responses clarified this point. The first evidence of this correlation was observed at histone $\mathrm{H} 3$ transient acetylation in the promoter region of al-3 [130]. An increase in acetylation was observed $20 \mathrm{~min}$ after multiple light pulses 
delivered to wild-type Neurospora strains in different light conditions, with a transient kinetic comparable to that of al-3 mRNA [150]. Lysine 14 (K14) has been shown to be involved in rhythmic acetylation after light pulse. Correlations between acetylation of acH3 K14 and transcriptional activation was confirmed in several other systems [151,152]. This was the first evidence that Neurospora light signal transduction involves chromatin modifications. Conversantly analysis of the acetylation state of core histones including AcH3 K9/K14 at the LRE region of the frq promoter did not show changes over the circadian cycle. Though this apparently contrasts with descriptions of the acetylation state of core histones at LRE regions, the discrepancy between these results may be due to differences in the loci examined and the regions therein[130,153].

A correlation between the transient acetylation of AcH3K14 and WCC activity was also demonstrated by the loss in light-dependent chromatin acetylation in a wc-1 null strain. Moreover, a Neurospora $h 3^{k 14 q}$ mutant, who carried an ectopic mutant copy of histone H3 (H3K14Q), engineered to substitute a lysine to glutamine at residue 14, showed the same light-dependent aberrant phenotype of the wc-1 null mutant [130]. Light-induced carotenogenesis was strongly impaired in the $h H 3 \mathrm{~K} 14 Q$ strain as compared with the isogenic wild type and this was coupled with a loss of light-inducible al-3 mRNA oscillation. Neurospora Gen Five-1 (NGF-1), a histone acetyl transferase homolog of yeast Gcn5p has also been found directly responsible for K14 H3 acetylation. This correlation was observed in the $n g f-1^{R I P 1}$ mutant strain in which the absence of NGF-1 HAT activity was coupled with a loss of histone acetylation at K14 of histone H3. Finally, $n g f-1^{R I P 1}$ and $w c-1$ null mutants exhibited identical phenotypes, suggesting that they are affected in the same signal transduction pathway. NGF-1 needs to physically interact with WC-1 in order to exert its own HAT activity [129]. Although this complex was preassembled in the dark, NGF-1 acetylated histones only after multiple light pulses (Figure 4). The more reasonable explanation is that, after multiple light pulses, a conformation shift in the region of the LOV domain of $\mathrm{WC}-1$ changes the NGF-1 position on the nucleosome, thus activating its HAT function [154]. NGF-1 is unable to acetylate histones without correct binding with the C-term region of WC-1. It has been found that the LXXLL consensus sequence of WC-1 is involved in the interaction with NGF-1. This is a conserved consensus used for the binding between nuclear receptors and coactivators $[155,156]$. This means that WC-1 acts as a nuclear receptor. This was the first time that this mechanism was observed in fungi and the first demonstration of WCC-mediated chromatin remodeling in light-dependent events in N. crassa [157]. 


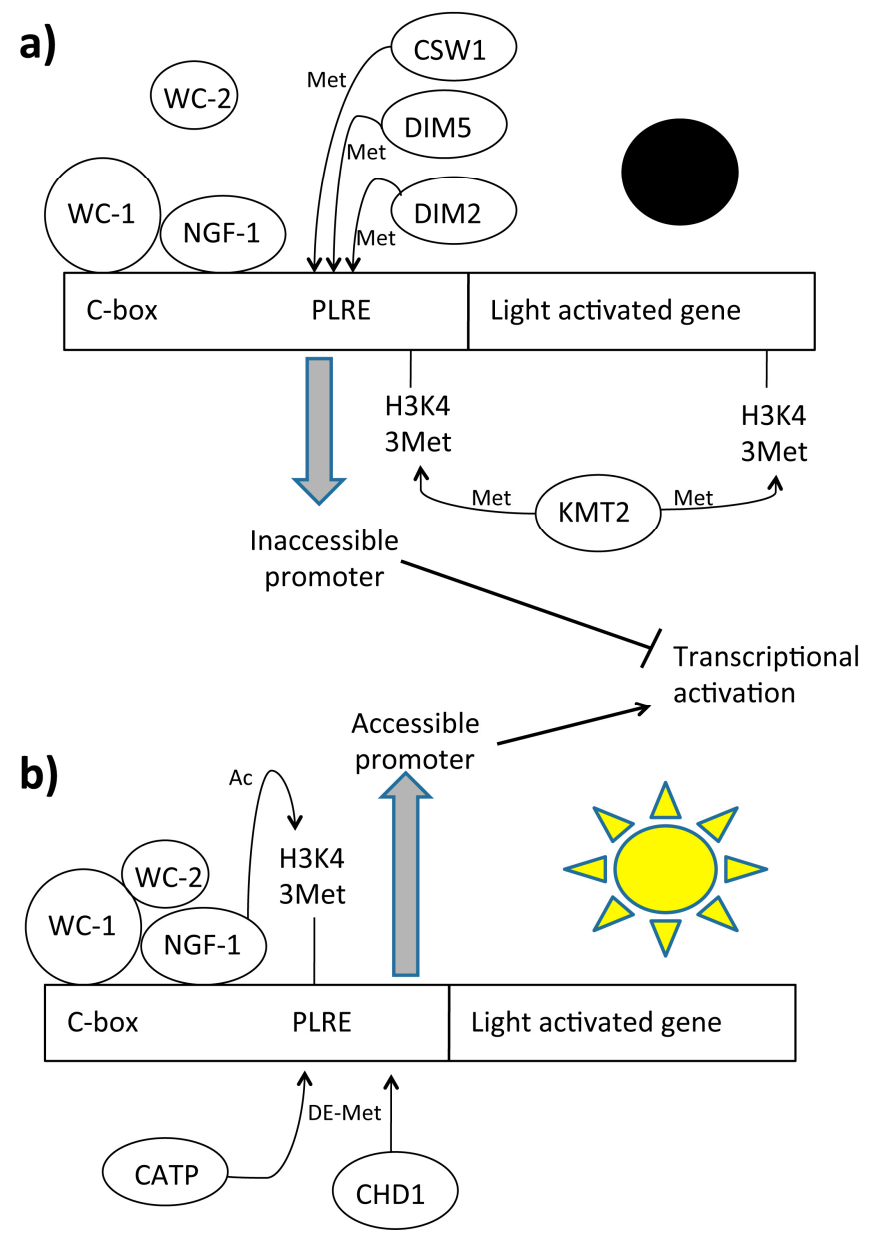

Figure 4. Light dependent chromatin remodeling on light activable genes. Legend: C-box: DNA box for protein specific interaction, CATP: Clock ATPase, CHD1: Chromo-domain helicase DNA-binding protein, CSW1: Clockswitch protein, DIM: Defective in protein methylation, KMT2: Histone methyltransferase Set1, NGF1: histone acetyltransferase homologous of GNC-5, PLRE: Proximal light-regulated element, WC-1: White Collar 1 protein, WC-2: White Collar 2 protein. (a) In dark conditions the methylases DIM2, DIM5, CSW1 and KMT2 generate a closed chromatin structure that prevents gene transcription; (b) Under light irradiation, NGF-1 acetylates H3K14 residues of light dependent regulatory elements of light activated genes. At the same time several demethylases such CHD1 and CATP remove the methyl groups added during the "dark conditions", generating a more accessible chromatin structure.

\subsection{Chromatin Remodeling Enzymes}

Multiple evidences suggest that dynamic histone accumulation and modification are under the control of the circadian cycle. Mouse Period 1 and Period 2 (mPerl and mPer2) genes, which encode central clock components functionally analogous to FRQ, have rhythmic AcH3 (K9, K14) modifications, and RNA polymerase II (Pol II) binds rhythmically to these promoters [144,151]. Since the mammalian clock gene mPer 2 has promoter methylation, chromatin remodeling and histone occupancy at the $f r q$ promoter region were analyzed. Transcriptional regulation at the frq promoter occurs through binding of the WC proteins to Clock box ( $\mathrm{C}$ box) required for rhythmic oscillation in 
constant darkness. It occurs by binding with proximal light-regulated elements (PLREs) as well, necessary for $f r q$ light-dependent activation [24,51]. Occupancy of the frq promoter by WCC and DNase hypersensitivity of this region show circadian oscillation, contrasting with the common idea of a stable, preassembled and obligated WCC in all daily conditions as described above [153,158]. ChIP assays showed rhythmic association of WC-2 but not of $\mathrm{WC}-1$ at the C-box, indicating a dynamic regulation that includes complex formation or disassembly. Moreover, at the PLRE region it was observed that WC-1 but not WC-2 is present in all circadian times. This means that accessibility to DNA by transcription factors is cyclically regulated during the day.

The ATP-dependent chromatin-remodeling enzyme CSW-1 is thought to be responsible for the closing catalytic activity [153]. Molecular and genotypic data showed that CSW-1 negatively regulates WCC activity by changing chromatin accessibility at the frq promoter. Indeed, strains lacking CSW-1 show a relatively open chromatin structure at the frq promoter. CSW-1 facilitates chromatin compaction and decrease of WC-2 levels at the frq promoter, thus promoting its repression. Translated FRQ cooperates to increase nucleosome occupancy and inhibit WCC binding at the C-box. Also, other enzymes that modify DNA methylation cooperate in chromatin compaction. The DNA methyltransferase (DNMT) DIM-2/HP1 (defective in methylation; heterochromatin protein-1) and DIM-5 are required for DNA methylation at frq promoter in circadian rhythmicity [159]. Deletion of dim-2 results in a small phase defect (approximately $2 \mathrm{~h}$ ) and changes in DNA methylation at frq. This indicates a link between DNA methylation and phasing of clock gene expression. Interestingly, DNA methylation at the $f r q$ promoter decreased with time in constant darkness, although not in an overtly circadian manner. Moreover, promoter methylation appeared greatly reduced in cultures grown in constant light for extended periods (48 $\mathrm{h}$ in light), providing evidence for another strong correlation between epigenetic modification and light signal transduction. Dim-5-dependent H3K9me3 is required for $f r q$ promoter methylation. Loss of DIM-5 can also suppress the hypermethylation phenotype of chd1 and the mutant show a shorter phase advantage compared with dim-2 mutant period [159]. DIM-5 DNA activity is also established in response to the light and loss of H3K9me3 results in elevated WCC binding to the frq promoter and an increase in light activated frq expression. All together these data suggest that $\mathrm{H} 3 \mathrm{~K} 9 \mathrm{me} 3$ appears to be involved light-mediated expression and is likely more important in the diurnal expression confirming that DNA methylation is required in the circadian entrainment. Antisense $q f r$ RNA is also essential for normal DNA methylation in this region. This DNA methylation at frq is surprising. Indeed, in various Neurospora strains analyzed in many different conditions in which about $2 \%$ of cytosines are methylated, methylation exists exclusively as a relic of repeat-induced point (RIP) mutation and rDNA [160,161]. Since all these factors are indispensable for chromatin compacting, others are involved in chromatin opening for the next round of activation. Clock ATPase (CATP) counteracts CSW-1 activity, opening the chromatin structure and positively regulating nucleosome occupancy at the frq locus [162]. It has been demonstrated that CATP promotes the removal of nucleosomes at the frq locus and enhances WCC binding. CATP activity, but not CATP expression, shows circadian oscillation, counteracting the increase in nucleosome occupancy at the C-box. CATP specifically associates with the frq locus, suggesting that CATP regulates nucleosome occupancy directly on chromatin. The catp ${ }^{K o}$ strain shows a lower expression of FRQ, higher occupancy at the frq C-box, and minor WCC occupancy during the day as 
compared with the wild-typestrain. Though it is not clear how CATP works, both the ATPase domain and the bromodomain of CATP are essential for its function in the clock.

Chromo-domain helicase DNA-binding protein 1 (CHD1), another chromatin remodeler, has been found to be involved in frq chromatin remodeling through which it promotes the open state of chromatin [158]. Loss of CHD1 generates hypermethylation on the frq locus. It was demonstrated that CHD1 is required for maintaining regular high amplitude rhythms of WC-2 binding, which contributes to the apparent changes in chromatin structure. DNA methylation has been also found in the promoter of $w c-1$ gene in the $d c h d 1$ mutant strain but absent in the wild-type strain. These data suggest that CHD1 acts as a demethyltransferase that counteracts DIM2 and qfr activity, though the molecular mechanism is not clear. Finally, these data highlight that DNA and histone methylation modulates light responses and circadian rhythms. Figure 4 illustrates the chromatin rearrangements on light-activated genes. Table 3 presents the chromatin remodelers and their activity.

Table 3. Putative modifications in frq promoter (PLRE and C-BOX).

\begin{tabular}{ccccc}
\hline Enzyme & Modification & Target & Activation & Deactivation \\
\hline NGF1 & Acetylation & H3K9-H3K14 & X & - \\
DIM-2 & Methylation & Undefined & - & X \\
DIM-5 & Methylation & H3K9 & - & X \\
CSW-1 & De-Acetylation & Undefined & - & X \\
KMT2 & 3Methylation & H3K4 & - & X \\
CATP & Demethylation & Undefined & X & - \\
CHD1 & Demethylation & Undefined & X & - \\
\hline
\end{tabular}

Every enzyme is tagged with a specific feature as "activation" or "deactivation" by marking with an $\mathrm{X}$ in the proper column.

\subsection{Chromatin Methylation}

Other factors cooperate with CSW-1 for chromatin compaction. The KMT2 enzyme, called SET1 (FGSC15827), has been isolated as a candidate for circadian and light-dependent histone methylation [163]. SET1 is part of a large holoenzymatic complex (complex associated with SET1 [COMPASS]) that contains several additional subunits involved in H3K4 methylation [164]. Strains lacking set1 gene or a subset of other SET1/COMPASS subunits have an apparent arrhythmic clock phenotype on race tubes. Moreover, in analysis at transcriptional and translational levels confirmed the defect of $\mathrm{frq}$ in the set 1 mutant strain indicating that $\mathrm{H} 3 \mathrm{~K} 4$ methylation is required for efficient feedback inhibition of the central clock gene.

ChIP data indicate that $\mathrm{H} 3 \mathrm{~K} 4 \mathrm{me} 3$ is present at the frq locus throughout the entire circadian cycle, with peaks occurring during the transcriptional repressive phase (CT9 to CT13) corresponding to the repressive phase of $f r q$ transcription. H3K4me3 is predominantly present in the frq-coding region, which is consistent with reports that $\mathrm{H} 3 \mathrm{~K} 4$ methylation is normally localized to coding regions and the transcriptional start site of genes [165]. This methylation is strongly regulated by SET1. Indeed, there is a delay in the temporal $\mathrm{H} 3 \mathrm{~K} 4$ methylation of the frq promoter in $\Delta$ set 1 mutant strains compared with wild-type strains. This delay increases the amplitude of frq expression under circadian and light-dependent conditions. This further suggests that $\mathrm{H} 3 \mathrm{~K} 4 \mathrm{me} 3$ may play a role in the down-regulation of frq. 
Moreover, lack of functional SET1 causes a temporal alteration of rhythms in conidia formation. A defect in WC-2 binding to the C-box element in $\Delta$ set 1 mutant has been observed as consequence of the altered histone methylation state.

In wild-type Neurospora strains, no changes in $\mathrm{H} 3 \mathrm{~K} 4$ methylation were observed after exposure to light for $15 \mathrm{~min}$ at the PLRE. After $30 \mathrm{~min}$, a time corresponding to the start of VIVID (VVD)-dependent light repression, the $\mathrm{H} 3 \mathrm{~K} 4 \mathrm{me} 3$ levels rose and remained elevated, followed by a slow and steady decrease over the course of the next $2 \mathrm{~h}$. This suggests that SET-1 can play a role also in light-dependent processes. These data confirm that histone methylation is necessary for modulating circadian and light responses by chromatin compaction. Figure 4 summarizes the factors involved in Chromatin methylation.

\section{Conclusions}

Post Translational Modifications (PTMs) generally influence oscillation of clock components and these modifications are strongly conserved among species [166,167]. In this review we discussed how PTMs can influence light responses and circadian rhythms in N. crassa and how they are involved in protein activity and chromatin remodeling. As shown in Figure 5 we propose a model on the basis of the data discussed above.

In constant darkness newly synthesized WC-1 and WC-2 dimerizes in the cytoplasm to form the WCC complex. Hyperphosphorylated FRQ seems to be necessary for assembling the WCC but its actual function remains to be elucidated. WCC translocates into the nucleus and binds the clock-controlled frequency promoter gene at the C-box. The hypophosphorylated WCC is better able to bind the promoter of clock-controlled genes, leading to their transcriptional activation. At the same time, the WCC activates a still uncharacterized WC-2 repressor that inhibits $w c-2$ gene expression, generating a negative feedback loop in WCC production. After transcriptional activation, frq mRNA is exported into the cytoplasm and translated. The hypophosphorylated FRQ protein is then able to translocate into the nucleus and homodimerizes via its N-terminal domain. The homodimeric FRQ protein forms a complex with FRQ-interacting RNA helicase (FRH), termed the FRQ-FRH complex (FFC), which functions similarly to PERs and CRYs in mammals. This complex physically interacts with the WCC and it recruits several kinases, including CKa, CKb, CKII PKA and GSK3 $\beta$, which balance FRQ circadian stability.

At the same time, PKA, the WCC priming kinase, phosphorylates $\mathrm{WC}-1$ at $\mathrm{S} 990$ in an FRQ-independent pathway, driving the WC-1 phosphorylation mediated by $\mathrm{CKa}$ and $\mathrm{CKII}$ in a FRQ-dependent manner. FRQ changes its conformation after the first phosphorylation at the N-terminal domain, resulting in disassembly of the FCC complex. FRQ then exposes the PEST domain and other phosphorylating sites. WC-1 is subsequently phosphorylated at S992, S994, S998 sites close to the zinc-finger domain required for WC-1 dark activation. WC-2 is target of many not yet defined phosphorylation. Many phosphatases, including PP1, PP2a, and PP4, counteract kinase activities, stabilize the FRQ protein, and regulate the timing of its turnover. The hyperphosphorylated FRQ is exported into the cytoplasm, thereby driving the WCC shuttling and ensuring the FRQ-dependent clearance of the WC-1 from the nucleus. Finally, FRQ is ubiquitinated and targeted to the proteasome by F-box and WD40 repeat-containing protein 1 (FWD-1). Since phosphorylated WCC is no longer able to activate gene transcription, the FRQ level drastically decreases and the negative loop closes. WC-1 is recycled for a new circadian cycle in constant darkness. 


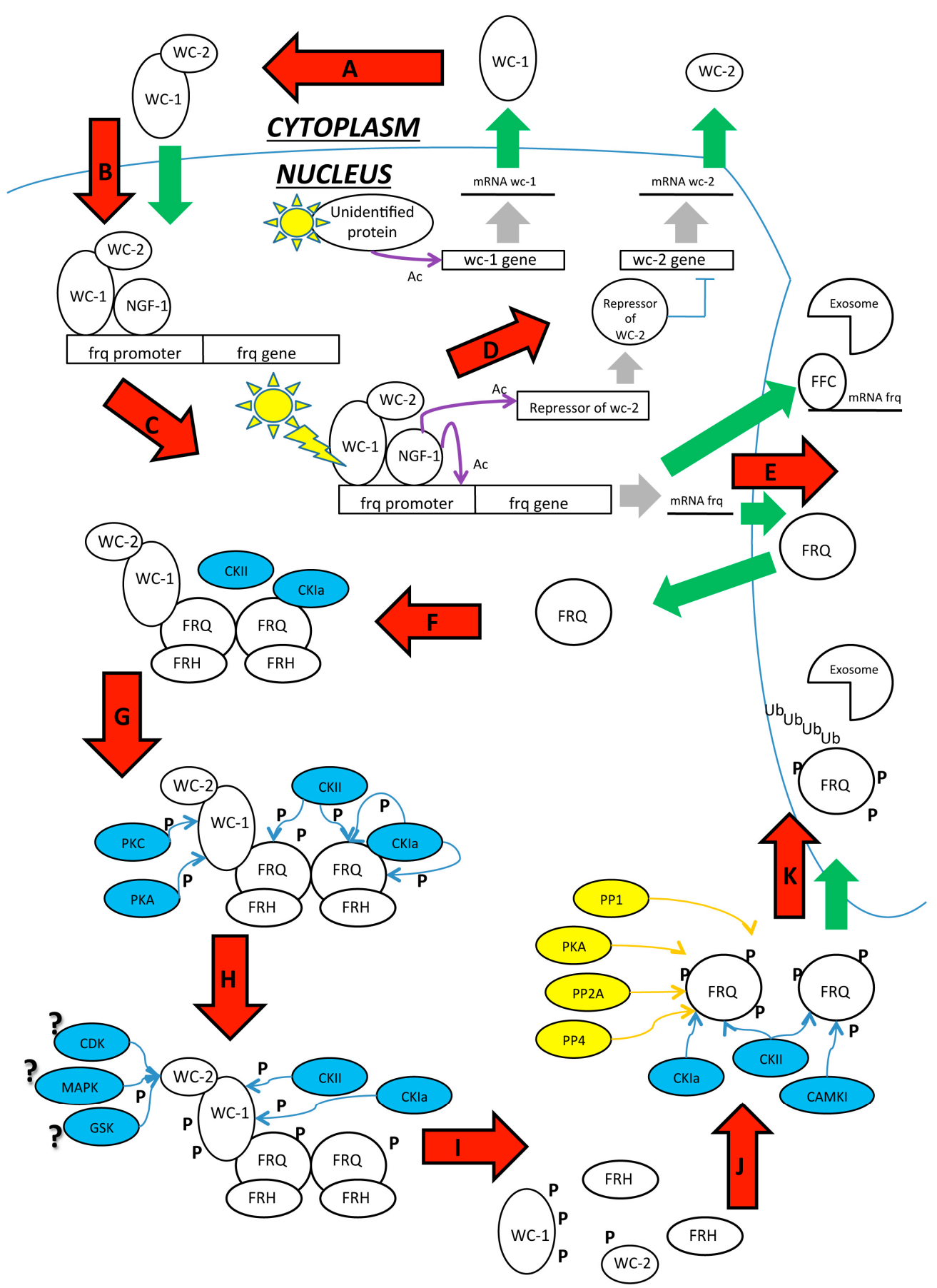

Figure 5. Scheme reporting the major PTM identified in the process of the circadian clock in $N$. crassa. This figure summarizes the single figures showed in the paper. Legend and Symbols: ? = Supposed, Ac: Acetyl group, Blue arrows: Phosphorylation, Blue circles: Kinases, Green arrows: import/export, Grey arrows: transcription, P: Phosphate group, Ub: Ubiquitin, Violet arrows: Acetylation, Yellow arrows: De-phosphorylation, Yellow circles: De-phosphorylates. (A) WC-1 and WC-2 presumably dimerize in the cytoplasm where they form the WCC that shuttlesinto the nucleus; (B) Here, the WCC recruits the inactive acetyltransferase NGF1 and binds the promoter of light-dependent genes; (C) After light pulse, the WCC changes conformation due to the LOV domain of WC-1, NGF1 is positioned onto the chromatin of the target genes $v v d$ and al-3, and histone acetylation relaxes the chromatin. Frq mRNA is transcribed as well; (D) The WCC also 
activates the transcription of an unidentified repressor of the $w c-2$ gene that blocks the production of WC-2 protein, generating a negative feedback on the WCC; (E) Frq mRNA is exported into the cytoplasm where it is translated. The hypophosphorylated FRQ is rapidly imported into the nucleus; (F) FRQ homodimerizes and recruits FRH that ensures proper FRQ folding. FRQ also recruits the kinases CKIa and CKII, generating the FFC. Finally, the FFC physically interacts with the WCC. High levels of FFC are responsible for frq mRNA degradation by targeting the transcript to the exosome (E); (G) CKIa and CKII phosphorylate the FRQ C-terminal domain. PKA and PKC phosphorylate WC-1 on S990 and S995, which is signal that targets the other serines for subsequent phosphorylation; (H) CKIa and CKII start to phosphorylate WC-1 at S992, S994, S998. WC-2 S443 is targeted by undefined FRQ-independent kinases; (I) Phosphate groups abolish the acidic properties of the FRQ N-terminal domain, disassembling the FFC. Phosphorylation also inhibits the interaction between FFC and WCC, causing the loop to close; (J) FRQ exposes its PEST domains and other phosphorylation sites. Numerous dephosphorylases contrast the kinase activity, stabilizing the protein and regulating FRQ half-life. The hyperphosphorylated FRQ is ubiquitinated and targeted for proteasomal degradation.

Transcription of clock-controlled genes is also affected by DNA methylation, histone modifications, and nucleosome assembly/exchange. Occupancy of the frq promoter at the $C$ box by the WCC and DNase hypersensitivity of this region shows circadian oscillation as well. The ATP-dependent chromatin remodeling enzyme Clockswitch (CSW-1), the DNA methyltransfrase DIM-2/HP1, the H3K9me3 dependent DIM-5, the antisense transcript qrf, the histone H3K4 methyltransferase SET1, and the translated FRQ all cooperate to compact the chromatin. They are counteracted by Clock ATPase (CATP) and CHD-1 that cooperate to open the chromatin structure, allowing the exposure of the C-box or light responsive elements (LREs). Moreover, the WCC also recruits the SWI/SNF (SWItch/Sucrose NonFermentable) complex that aids to remove the nucleosome from the $C$ box and bends the DNA to bring the TSS close to the $\mathrm{C}$ box and the WCC, promoting transcriptional activation [168]. SWI/SNF is an ATP-dependent chromatin-remodeling complex that alters chromatin structure and helps in transcriptional activation, DNA repair, recombination and segregation $[169,170]$.

In constant darkness conditions, the WCC also recruits histone acetyltransferase NGF-1 and binds dependent gene promoters at the LREs al-3 or vivid. Probably, NGF-1 is recruited also onto the frq LRE, but this interaction has not yet been demonstrated. After multiple light pulses, the WCC undergoes LOV-mediated conformation and positions NGF-1 onto the promoter of the target genes. The light-dependent H3K14 acetylation mediated by NGF-1 activates light-dependent gene transcription. The H3K14 acetylation decreases in amplitude when WCC becomes hyperphosphorylated in a light-dependent manner. The phosphorylation is mediated by PKC and FRQ-complex and dissociates the WCC from the promoter of its target genes and reduces promoter acetylation, causing the transcription to switch off. This leads to a decrease in frq mRNA and protein amount, which closes the light-dependent negative loop. After the light/dark switch, reactivation of WC-1 can generate a new circadian cycle or light-dependent responses.

The conservation of the posttranslational mechanisms is remarkable among different eukaryotic circadian systems from prokaryotes to humans [82]. 
Cyanobacteria are the most ancient example of Post Translational Modifications-mediated circadian oscillation in which the cell-self sustained circadian period length and its stability are derived from the ATPase activity of KaiC kinase [171-173].

There are several strands of evidence supporting the idea of a conserved molecular mechanism between mammals and Neurospora. Similar to FRQ/WCs, animal and plant clock proteins are regulated at post-translational level. Period proteins, members of the negative loop in the fly (PER) and mammalian (mPER2) circadian clock, are progressively phosphorylated and degraded [174,175]. The mammalian Bmal1, Clock and Cry also exhibit robust rhythms in their phosphorylation profiles [176-181].

In addition, FRQ and the animal PER proteins are phosphorylated by CKI and CKII, dephosphorylated by the same phosphatases, and degraded by the ubiquitin/proteasome system using a conserved E3 ubiquitin ligase [75-79,90-114].

Furthermore, a antisense of the per RNA has recently been discovered that should work as a qrf [182]. All together these evidences further confirmed the presence of a conserved mechanism involved in circadian clock and light signal transduction across living kingdoms. This holds interest for research in Neurospora, which, because of its rapid life cycle, availability of a large number of mutations and ease of manipulation, provides a useful model system for studying circadian clock and light signal transduction pathways. This makes $N$. crassa a powerful tool for improving our understanding of the epigenetic and posttranslational regulations of circadian rhythms that are highly conserved across species.

\section{Acknowledgments}

The authors thank the Lab5 staff for their critical contribution to this review, in particular Patrizia Filetici and Claudia Canzonetta. Paola Ballario received funds from the Pasteur Cenci-Bolognetti Foundation and the Sapienza-University of Rome.This work was supported by Sapienza University of Rome (CA26A147BSJ) and Ministero degli Esteri e della Cooperazione Internazionale, Direzione generale per la Promozione del Sistema Paese (MX14MO08). Andrea Brenna is a Post Doc paid from Pasteur Institute_Cenci Bolognetti Foundation. Marco Proietto is a $\mathrm{PhD}$ student at Sapienza-University of Rome paid from CNR-National Research Council.

\section{Author Contributions}

All authors contributed equally to manuscript writing.

Andrea Brenna proposed the topic. Marco Proietto prepared tables the figures. Michele Maria Bianchi provided funding and critical reading, Paola Ballario supervised the entire work.

\section{Conflicts of Interest}

The authors declare no conflict of interest.

\section{References}

1. Cashmore, A.R.; Jarillo, J.A.; Wu, Y.J.; Liu, D. Cryptochromes: Blue light receptors for plants and animals. Science 1999, 284, 760-765. 
2. Ahmad, M.; Cashmore, A.R. The HY4 gene of A. thaliana encodes a protein with characteristics of a blue-light photoreceptor. Nature 1993, 366, 162-166.

3. Short, T.W.; Briggs, W.R. The transduction of blue light signals in higher plants. Annu. Rev. Plant Physiol. Plant Mol. Biol. 1994, 45, 143-171.

4. Fankhauser, C. The phytochromes, a family of red/far-red absorbing photoreceptors. J. Biol. Chem. 2001, 276, 11453-11456.

5. Linden, H.; Ballario, P.; Macino, G. Blue light regulation in Neurospora crassa. Fungal Genet. Biol. 1997, 3, 141-150.

6. Galagan, J.E.; Calvo, S.E.; Borkovich, K.A.; Selker, E.U.; Read, N.D.; Jaffe, D.; FitzHugh, W.; Ma, L.J.; Smirnov, S.; Purcell, S.; et al. The genome sequence of the filamentous fungus Neurospora crassa. Nature 2003, 422, 859-868.

7. Froehlich, A.C.; Noh, B.; Vierstra, R.D.; Loros, J.; Dunlap, J.C. Genetic and molecular analysis of phytochromes from the filamentous fungus Neurospora crassa. Eukaryot. Cell 2005, 12, $2140-2152$.

8. Arpaia, G.; Loros, J.; Dunlap, J.C.; Morelli, G.; Macino, G. The circadian clock-controlled gene ccg-J is induced by light. Mol. Gen. Genet. 1995, 247, 157-163.

9. Harding, R.W.; Turner, R.V. Photoregulation of the carotenoid biosynthetic pathways in albino and white collar mutants of Neurospora crassa. Plant Physiol. 1981, 68, 745-749.

10. Lauter, F.R.; Russo, V.E. Blue light induction of conidiation-specific genes in Neurospora crassa. Nucleic Acids Res. 1991, 19, 6883-6886.

11. Harding, R.W.; Melles, S. Genetic analysis of the phototrophism of Neurospora crassa perithecial beaks using white collar and albino mutants. Plant Physiol. 1984, 72, 996-1000.

12. Corrochano, L.M. Fungal photoreceptors: Sensory molecules for fungal development and behaviour. Photochem. Photobiol. Sci. 2007, 7, 725-736.

13. Herrera-Estrella, A.; Horwitz, B.A. Looking through the eyes of fungi: Molecular genetics of photoreception. Mol. Microbiol. 2007, 64, 5-15.

14. Nelson, M.A.; Morelli, G.; Carattoli, A.; Romano, N.; Macino, G. Molecular cloning of Neurospora crassa carotenoid biosynthetic gene (albino-3) regulated by blue light and the product of the white collar-1 gene. Mol. Cell. Biol. 1989, 9, 1271-1276.

15. Schmidhauser, T.J.; Lauter, F.R.; Russo, E.A.; Janofsky, C. Cloning, sequence and photoregulation of al-l, a carotenoid biosynthetic gene of Neurospora crassa. Mol. Cell. Biol. 1990, 10, 5064-5070.

16. Chen, C.H.; Ringelberg, C.S.; Gross, R.H.; Dunlap, J.C.; Loros, J.J. Genome-wide analysis of light-inducible responses reveals hierarchical light signalling in Neurospora. EMBO J. 2009, 28, 1029-1042.

17. Chen, C.H.; Dunlap, J.C.; Loros, J.J. Neurospora illuminates fungal photoreception. Fungal Genet. Biol. 2010, 47, 922-929.

18. Ballario, P.; Vittorioso, P.; Magrelli, A.; Talora, C.; Cabibbo, A.; Macino, G. White collar-1, a central regulator of blue light responses in Neurospora, is a zinc finger protein. EMBO J. 1996, 15, 1650-1657.

19. Linden, H.; Macino, G. White collar 2, a partner in blue-light signal transduction, controlling expression of light-regulated genes in Neurospora crassa. EMBO J. 1997, 16, 98-109. 
20. Ballario, P.; Talora, C.; Galli, D.; Linden, H.; Macino, G. Roles in dimerization and blue light photoresponse of the PAS and LOV domains of Neurospora crassa white collar proteins. Mol. Microbiol. 1998, 29, 719-729.

21. Dunlap, J.C.; Loros, J.J. Neurospora photoreceptors. In Handbook of Photosensory Receptors; Briggs, W.R., Spudich, J.L., Eds.; Wiley-VCH Verlag GmbH \& Co: Weinheim, Germany, 2005; pp. 371-389.

22. Christie, J.M.; Salomon, M.; Nozue, K.; Wada, M.; Briggs, W.R. LOV (light, oxygen, or voltage) domains of the blue-light photoreceptor phototropin (nph1): Binding sites for the chromophore flavin mononucleotide. Proc. Natl. Acad. Sci. USA 1999, 96, 8778-8783.

23. Schafmeier, T.; Kaldi, K.; Diernfellner, A.; Mohr, C.; Brunner, M. Phosphorylation-dependent maturation of Neurospora circadian clock protein from a nuclear repressor toward a cytoplasmic activator. Genes Dev. 2006, 20, 297-306.

24. Froehlich, A.C.; Liu, Y.; Loros, J.J.; Dunlap, J.C. White Collar-1, a circadian blue light photoreceptor, binding to the frequency promoter. Science 2002, 297, 815-819.

25. Sancar, C.; Ha, N.; Yilmaz, R.; Tesorero, R.; Fisher, T.; Brunner, M.; Sancar, G. Combinatorial control of light induced chromatin remodeling and gene activation in Neurospora. PLoS Genet. 2015, 3, e1005105.

26. Cheng, P.; Yang, Y.; Wang, L.; He, Q.; Liu, Y. WHITE COLLAR-1, a multifunctional Neurospora protein involved in the circadian feedback loops, light sensing, and transcription repression of wc-2. J. Biol. Chem. 2003, 278, 3801-3808.

27. He, Q.; Liu, Y. Molecular mechanism of light responses in Neurospora: From light-induced transcription to photoadaptation. Genes Dev. 2005, 19, 2888-2899.

28. Sommer, G.J.; Chambers, A.A.; Eberle, J.; Lauter, F.R.; Russo, V.E. Fast light-regulated genes of N. crassa. Nucleic Acids Res. 1989, 17, 5717-5724.

29. Arpaia, G.; Loros, J.; Dunlap, J.C.; Morelli, G.; Macino, G. The interplay of light and the circadian clock: Independent dual regulation of clock-controlled gene cg-2(eas). Plant Physiol. 1993, 102, 1299-1305.

30. Arpaia, G.; Carattoli, A.; Macino, G. Light and development regulate the expression of the albino-3 gene in Neurospora crassa. Dev. Biol. 1995, 170, 626-635.

31. Neiss, A.; Schafmeier, T.; Brunner, M. Transcriptional regulation and function of the Neurospora clock gene white collar 2 and its isoforms. EMBO Rep. 2008, 9, 788-794.

32. Heintzen, C.; Loros, J.J.; Dunlap, J.C. The PAS protein VIVID defines a clock-associated feedback loop that represses light input, modulates gating, and regulates clock resetting. Cell 2001, 104, 453-464.

33. Zoltowski, B.D.; Crane, B.R. Light activation of the LOV protein VIVID generates a rapidly exchanging dimer. Biochemistry 2008, 47, 7012-7019.

34. He, Q.; Cheng, P.; Yang, Y.; Wang, L.; Gardner, K.H.; Liu, Y. White collar-1, a DNA binding transcription factor and a light sensor. Science 2002, 297, 840-843.

35. Malzahn, E.; Ciprianidis, S.; Kaldi, K.; Schafmeier, T.; Brunner, M. Photoadaptation in Neurospora by competitive interaction of activating and inhibitory LOV domains. Cell $\mathbf{2 0 1 0}$, 142, 762-772.

36. Schibler, U.; Sassone-Corsi, P. A web of circadian pacemakers. Cell 2002, 111, 919-922. 
37. Woelfle, M.A.; Ouyang, Y.; Phanvijhitsiri, K.; Johnson, C.H. The adaptive value of circadian clocks: An experimental assessment in cyanobacteria. Curr. Biol. 2004, 14, 1481-1486.

38. Dunlap, J.C. Molecular bases for circadian clocks. Cell 1999, 96, 271-290.

39. Albrecht, U. Circadian rhythms: A fine c(l)ocktail! Curr. Biol. 2001, 11, 517-519.

40. Pittendrigh, C.S. Circadian rhythms and the circadian organization of living systems. Cold Spring Harb. Symp. Quant. Biol. 1960, 25, 159-184.

41. Stadler, D.R. Genetic control of a cyclic growth pattern in Neurospora. Nature 1959, 184, 170-171.

42. Sussman, A.S.; Durkee, T.L.; Lowry, R.J. A model for rhythmic and temperature-independent growth in "clock" mutants of Neurospora. Mycopathol. Mycol. Appl. 1965, 25, 381-396.

43. Sargent, M.L.; Briggs, W.R.; Woodward, D.O. Circadian nature of a rhythm expressed by an invertaseless strain of Neurospora crassa. Plant Physiol. 1966, 41, 1343-1349.

44. Berliner, M.D.; Neurath, P.W. The band forming rhythm of Neurospora mutants. J. Cell. Physiol. 1965, 65, 183-193.

45. Baker, C.L.; Loros, J.J.; Dunlap, J.C. The circadian clock of Neurospora crassa. FEMS Microbiol. Rev. 2012, 36, 95-110.

46. Crosthwaite, S.K.; Dunlap, J.C.; Loros, J.J. Neurospora $w c-1$ and $w c-2$ : Transcription, photoresponses, and the origins of circadian rhythmicity. Science 1997, 276, 763-769.

47. Aronson, B.D.; Johnson, K.A.; Loros, J.J.; Dunlap, J.C. Negative feedback defining a circadian clock: Autoregulation of the clock gene frequency. Science 1994, 263, 1578-1584.

48. Gorl, M.; Merrow, M.; Huttner, B.; Johnson, J.; Roenneberg, T.; Brunner, M. A PEST-like element in FREQUENCY determines the length of the circadian period in Neurospora crassa. EMBO J. 2001, 20, 7074-7084.

49. Liu, Y.; Loros, J.; Dunlap, J.C. Phosphorylation of the Neurospora clock protein FREQUENCY determines its degradation rate and strongly influences the period length of the circadian clock. Proc. Natl. Acad. Sci. USA 2000, 97, 234-239.

50. Cheng, P.; Yang, Y.; Gardner, K.H.; Liu, Y. PAS domain-mediated WC-1/WC-2 interaction is essential for maintaining the steady-state level of $\mathrm{WC}-1$ and the function of both proteins in circadian clock and light responses of Neurospora. Mol. Cell. Biol. 2002, 22, 517-524.

51. Froehlich, A.C.; Loros, J.J.; Dunlap, J.C. Rhythmic binding of a WHITE COLLAR-containing complex to the frequency promoter is inhibited by FREQUENCY. Proc. Natl. Acad. Sci. USA 2003, 100, 5914-5919.

52. Heintzen, C.; Liu, Y. The Neurospora crassa circadian clock. Adv. Genet. 2007, 58, 25-66.

53. Zhou, M.; Guo, J.; Cha, J.; Chae, M.; Chen, S.; Barral, J.M.; Sachs, M.S.; Liu, Y. Non-optimal codon usage affects expression, structure and function of clock protein FRQ. Nature 2013, 495, 111-115.

54. Diernfellner, A.; Colot, H.V.; Dintsis, O.; Loros, J.J.; Dunlap, J.C.; Brunner, M. Long and short isoforms of Neurospora clock protein FRQ support temperature-compensated circadian rhythms. FEBS Lett. 2007, 581, 5759-5764.

55. Luo, C.; Loros, J.J.; Dunlap, J.C. Nuclear localization is required for function of the essential clock protein FRQ. EMBO J. 1998, 17, 1228-1235.

56. Lewis, M.T.; Morgan, L.W.; Feldman, J.F. Analysis of frequency ( $f r q$ ) clock gene homologs: Evidence for a helix-turn-helix transcription factor. Mol. Gen. Genet. 1997, 4, 401-414. 
57. Colot, H.V.; Loros, J.J.; Dunlap, J.C. Temperature-modulated alternative splicing and promoter use in the Circadian clock gene frequency. Mol. Biol. Cell 2005, 12, 5563-5571.

58. Liu, Y.; Garceau, N.Y.; Loros, J.J.; Dunlap, J.C. Thermally regulated translational control of FRQ mediates aspects of temperature responses in the Neurospora circadian clock. Cell 1997, 89, 477-486.

59. Cheng, P.; He, Q.; Wang, L.; Liu, Y. Regulation of the Neurospora circadian clock by an RNA helicase. Genes Dev. 2005, 19, 234-241.

60. Shi, M.; Collett, M.; Loros, J.J.; Dunlap, J.C. FRQ-interacting RNA helicase mediates negative and positive feedback in the Neurospora circadian clock. Genetics 2010, 267, 414-422.

61. Guo, J.; Cheng, P.; Yuan, H.; Liu, Y. The exosome regulates circadian gene expression in a posttranscriptional negative feedback loop. Cell 2009, 138, 1236-1246.

62. Hong, C.I.; Ruoff, P.; Loros, J.J.; Dunlap, J.C. Closing the circadian negative feedback loop: FRQ-dependent clearance of WC-1 from the nucleus. Genes Dev. 2008, 22, 3196-3204.

63. Hurley, J.M.; Larrondo, L.F.; Loros, J.J.; Dunlap, J.C. Conserved RNA helicase FRH acts nonenzymatically to support the intrinsically disordered Neurospora clock protein FRQ. Mol. Cell 2013, 52, 832-843.

64. Lee, K.; Loros, J.J.; Dunlap, J.C. Interconnected feedback loops in the Neurospora circadian system. Science 2000, 289, 107-110.

65. Cheng, P.; Yang, Y.; Liu, Y. Interlocked feedback loop contribute to the robustness of the Neurospora circadian clock. Proc. Natl. Acad. Sci. USA 2001, 98, 7408-7413.

66. Diernfellner, A.C.; Querfurth, C.; Salazar, C.; Hofer, T.; Brunner, M. Phosphorylation modulates rapid nucleocytoplasmic shuttling and cytoplasmic accumulation of Neurospora clock protein FRQ on a circadian time scale. Genes Dev. 2009, 23, 2192-2200.

67. Cha, J.; Yuan, H.; Liu, Y. Regulation of the activity and cellular localization of the circadian clock protein FRQ. J. Biol. Chem. 2011, 286, 11469-11478.

68. Hong, C.I.; Jolma, I.W.; Loros, J.J.; Dunlap, J.C.; Ruoff, P. Simulating dark expressions and interactions of frq and wc-1 in the Neurospora circadian clock. Biophys. J. 2008, 15, 1221-1232.

69. Van der Steen, T.; Tindall, D.J.; Huang, H. Posttranslational modification of the androgen receptor in prostate cancer. Int. J. Mol. Sci. 2013, 14, 14833-14859.

70. Ngounou Wetie, A.G.; Woods, A.G.; Darie, C.C. Mass spectrometric analysis of post-translational modifications (PTMs) and protein-protein interactions (PPIs). Adv. Exp. Med. Biol. 2014, 806, 205-235.

71. Sabò, A.; Lusic, M.; Cereseto, A.; Giacca, M. Acetylation of conserved lysines in the catalytic core of cyclin-dependent kinase 9 inhibits kinase activity and regulates transcription. Mol. Cell. Biol. 2008, 28, 2201-2212.

72. Pegoraro, M.; Tauber, E. Animal clocks: A multitude of molecular mechanisms for circadian timekeeping. Wiley Interdiscip. Rev. RNA 2011, 2, 312-320.

73. Weber, F.; Zorn, D.; Rademacher, C.; Hung, H.C. Post-translational timing mechanisms of the Drosophila circadian clock. FEBS Lett. 2011, 10, 1443-1449.

74. Kusakina, J.; Dodd, A.N. Phosphorylation in the plant circadian system. Trends Plant Sci. 2012, $17,575-583$. 
75. Syed, S.; Saez, L.; Young, M.W. Kinetics of Doubletime kinase-dependent degradation of the Drosophila period protein. J. Biol. Chem. 2011, 31, 27654-27662.

76. Ko, H.W.; Jiang, J.; Edery, I. Role for Slimb in the degradation of Drosophila Period protein phosphorylated by Doubletime. Nature 2002, 420, 673-678.

77. Price, J.L.; Fan, J.Y.; Keightley, A.; Means, J.C. The role of casein kinase I in the Drosophila circadian clock. Methods Enzymol. 2015, 551, 175-195.

78. Eide, E.J.; Woolf, M.F.; Kang, H.; Woolf, P.; Hurst, W.; Camacho, F.; Vielhaber, E.L.; Giovanni, A.; Virshup, D.M. Control of mammalian circadian rhythm by CKI $\varepsilon$-regulated proteasome-mediated PER2 degradation. Mol. Cell. Biol. 2005, 7, 2795-2807.

79. Shanware, N.P.; Hutchinson, J.A.; Kim, S.H.; Zhan, L.; Bowler, M.J.; Tibbetts, R.S. Casein kinase 1-dependentphosphorylationof familial advanced sleep phase syndrome-associated residues controls PERIOD 2 stability. J. Biol. Chem. 2011, 14, 12766-12774.

80. Mahesh, G.; Jeong, E.; Ng, F.S.; Liu, Y.; Gunawardhana, K.; Houl, J.H.; Yildirim, E.; Jones, R.; Amunugama, R.; Allen, D.L.; et al. Phosphorylation of the transcription activator CLOCK regulates progression through a $\sim 24$-h feedback loop to influence the circadian period in Drosophila. J. Biol. Chem. 2014, 289, 19681-19693.

81. Kwak, Y.; Jeong, J.; Lee, S.; Park, Y.U.; Lee, S.A.; Han, D.H.; Kim, J.H.; Ohshima, T.; Suh, Y.H.; Mikoshiba, K.; et al. Cyclin-dependent kinase $5(\mathrm{Cdk} 5)$ regulates the function of CLOCK protein by direct phosphorylation. J. Biol. Chem. 2013, 288, 36878-36889.

82. Gallego, M.; Virshup, D.M. Post-translational modifications regulate the ticking of the circadian clock. Nat. Rev. Mol. Cell Biol. 2007, 8, 139-148.

83. Sanada, K.; Okano, T.; Fukada, Y. Mitogen-activated protein kinase phosphorylates and negatively regulates basic helix-loop-helix-PAS transcription factor BMAL1. J. Biol. Chem. 2002, 277, 267-271.

84. Tamaru, T.; Hirayama, J.; Isojima, Y.; Nagai, K.; Norioka, S.; Takamatsu, K.; Sassone-Corsi, P. CK2 $\alpha$ phosphorylates BMAL1 to regulate the mammalian clock. Nat. Struct. Mol. Biol. 2009, 16, 446-448.

85. Eide, E.J.; Vielhaber, E.L.; Hinz, W.A.; Virshup, D.M. The circadian regulatory proteins BMAL1 and cryptochromes are substrates of casein kinase Iepsilon. J. Biol. Chem. 2002, 277, 17248-17254.

86. Choudhary, C.; Kumar, C.; Gnad, F.; Nielsen, M.L.; Rehman, M.; Walther, T.C.; Olsen, J.V.; Mann, M. Lysine acetylation targets protein complexes and co-regulates major cellular functions. Science 2009, 325, 834-840.

87. Hirayama, J.; Sahar, S.; Grimaldi, B.; Tamaru, T.; Takamatsu, K.; Nakahata, Y.; Sassone-Corsi, P. CLOCK-mediated acetylation of BMAL1 controls circadian function. Nature 2007, 450, 1086-1090.

88. Nakahata, Y.; Kaluzova, M.; Grimaldi, B.; Sahar, S.; Hirayama, J.; Chen, D.; Guarente, L.P.; Sassone-Corsi, P. The NAD+-dependent deacetylaseSIRT1modulates CLOCK-mediated chromatin remodeling andcircadian control. Cell 2008, 134, 329-340.

89. Asher, G.; Gatfield, D.; Stratmann, M.; Reinke, H.; Dibner, C.; Kreppel, F.; Mostoslavsky, R.; Alt, F.W.; Schibler, U. SIRT1 regulates circadian clock gene expression through PER2 deacetylation. Cell 2008, 134, 17-28. 
90. Garceau, N.Y.; Liu, Y.; Loros, J.J.; Dunlap, J.C. Alternative initiation of translation and time-specific phosphorylation yield multiple forms of the essential clock protein FREQUENCY. Cell 1997, 89, 469-476.

91. Yang, Y.; Cheng, P.; Zhi, G.; Liu, Y. Identification of a calcium/calmodulin-dependent protein kinase that phosphorylates the Neurospora circadian clock protein FREQUENCY. J. Biol. Chem. 2001, 276, 41064-41072.

92. Querfurth, C.; Diernfellner, A.; Heise, F.; Lauinger, L.; Neiss, A.; Tataroglu, O.; Brunner, M.; Schafmeier, T. Posttranslational regulation of Neurospora circadian clock by CK1a-dependent phosphorylation. Cold Spring Harb. Symp. Quant. Biol. 2007, 72, 177-183.

93. Baker, C.L.; Kettenbach, A.N.; Loros, J.J.; Gerber, S.A.; Dunlap, J.C. Quantitative proteomics reveals a dynamic interactome and phase-specific phosphorylation in the Neurospora circadian clock. Mol. Cell 2009, 34, 354-363.

94. Merrow, M.W.; Dunlap, J.C. Intergenic complementation of a circadian rhythmicity defect: Phylogenetic conservation of structure and function of the clock gene frequency. EMBO J. 1994, 13, 2257-2566.

95. Roth, A.F.; Davis, N.G. Ubiquitination of the PEST-like endocytosis signal of the yeast a-factor receptor. J. Biol. Chem. 2000, 17, 8143-8153.

96. Diernfellner, A.C.; Schafmeier, T. Phosphorylations: Making the Neurospora crassa circadian clock tick. FEBS Lett. 2011, 585, 1461-1466.

97. Guo, J.; Cheng, P.; Liu, Y. Functional significance of FRH in regulating the phosphorylation and stability of Neurospora circadian clock protein FRQ. J. Biol. Chem. 2010, 285, 11508-11515.

98. He, Q.; Cha, J.; Lee, H.C.; Yang, Y.; Liu, Y. CKI and CKII mediate the FREQUENCY-dependent phosphorylation of the WHITE COLLAR complex to close the Neurospora circadian negative feedback loop. Genes Dev. 2006, 20, 2552-2565.

99. Kloss, B.; Price, J.L.; Saez, L.; Blau, J.; Rothenfluh, A.; Wesley, C.S.; Young, M.W. The Drosophila clock gene double-time encodes a protein closely related to human casein kinase I epsilon. Cell 1998, 94, 97-107.

100. Lauinger, L.; Diernfellner, A.; Falk, S.; Brunner, M. The RNA helicase FRH is an ATP-dependent regulator of CK1a in the circadian clock of Neurospora crassa. Nat. Commun. 2014, 5, 3598.

101. Tang, C.T.; Li, S.; Long, C.; Cha, J.; Huang, G.; Li. L.; Chen, S; Liu, Y. Setting the pace of the Neurospora circadian clock by multiple independent FRQ phosphorylation events. Proc. Natl. Acad. Sci. USA 2009, 106, 10722-10727.

102. Yang, Y.; Cheng, P.; He, Q.; Wang, L.; Liu, Y. Phosphorylation of FREQUENCY protein by casein kinase II is necessary for the function of the Neurospora circadian clock. Mol. Cell. Biol. 2003, 23, 6221-6228.

103. Yang, Y.; Cheng, P.; Liu, Y. Regulation of the Neurospora circadian clock by casein kinase II. Genes Dev. 2002, 16, 994-1006.

104. Cheng, P.; Yang, Y.; Heintzen, C.; Liu, Y. Coiled-coil domain-mediated FRQ-FRQ interaction is essential for its circadian clock function in Neurospora. EMBO J. 2001, 20, 101-108.

105. .Nakashima, H. Phase shifting of the circadian conidiation rhythm in Neurospora crassa by calmodulin antagonists. J. Biol. Rhythm. 1986, 2, 163-169. 
106. Sadakane, Y.; Nakashima, H. Light-induced phase shifting of the circadian conidiation rhythm is inhibited by calmodulin antagonists in Neurospora crassa. J. Biol. Rhythm. 1996, 11, 234-240.

107. Huang, G.; Chen, S.; Li, S.; Long, C.; Li, L.; He, Q.; Liu, Y. Protein kinase A and casein kinases mediate sequential phosphorylation events in the circadian negative feedback loop. Genes Dev. 2007, 21, 3283-3295.

108. Vanselow, K.; Vanselow, J.T.; Westermark, P.O.; Reischl, S.; Maier, B.; Korte, T.; Herrmann, A.; Herzel, H.; Schlosser, A.; Kramer, A. Differential effects of PER2 phosphorylation: Molecular basis for the human familial advanced sleep phase syndrome (FASPS). Genes Dev. 2006, 20, 2660-2672.

109. Xu, Y.; Toh, K.L.; Jones, C.R.; Shin, J.Y.; Fu, Y.H.; Ptácek, L.J. Modeling of a human circadian mutation yields insights into clock regulation by PER2. Cell 2007, 128, 59-70.

110. Hino, S.; Tanji, C.; Nakayama, K.; Kikuchi, A. Phosphorylation of beta-catenin by cyclic AMP-dependent protein kinase stabilizes beta-catenin through inhibition of its ubiquitination. Mol. Cell. Biol. 2005, 25, 9063-9072.

111. Van Veelen, W.; Le, N.H.; Helvensteijn, W.; Blonden, L.; Theeuwes, M.; Bakker, E.R.; Franken, P.F.; van Gurp, L.; Meijlink, F.; van der Valk, M.A.; et al. $\beta$-catenin tyrosine 654 phosphorylation increases Wnt signalling and intestinal tumorigenesis. Gut 2011, 60, 1204-1212.

112. Yang, Y.; He, Q.; Cheng, P.; Wrage, P.; Yarden, O.; Liu, Y. Distinct roles for PP1 and PP2A in the Neurospora circadian clock. Genes Dev. 2004, 18, 255-260.

113. Cha, J.; Chang, S.S.; Huang, G.; Cheng, P.; Liu, Y. Control of WHITE COLLAR localization by phosphorylation is a critical step in the circadian negative feedback process. EMBO J. 2008, 27, 3246-3255.

114. Cohen, P.T.; Philp, A.; Vázquez-Martin, C. Protein phosphatase 4-From obscurity to vital functions. FEBS Lett. 2005, 13, 3278-3286.

115. Querfurth, C.; Diernfellner, A.C.; Gin, E.; Malzahn, E.; Höfer, T.; Brunner, M. Circadian Conformational change of the Neurospora clock protein FREQUENCY triggered by clustered hyperphosphorylation of a Basic Domain. Mol. Cell 2011, 43, 713-722.

116. Cha, J.; Huang, G.; Guo, J.; Liu, Y. Posttranslational control of the Neurospora circadian clock. Cold Spring Harb. Symp. Quant. Biol. 2007, 72, 185-191.

117. Leung, P.C.; Taylor, W.A.; Wang, J.H.; Tipton, C.L. Ophiobolin A. A natural product inhibitor of calmodulin. J. Biol. Chem. 1984, 10, 2742-2747.

118. He, Q.; Cheng, P.; Yang, Y.; Yu, H.; Liu, Y. FWD1-mediated degradation of FREQUENCY in Neurospora establishes a conserved mechanism for circadian clock regulation. EMBO J. 2003, 22, 4421-4430.

119. Lauter, F.R.; Russo, V.A. Light-induced dephosphorylation of a $33 \mathrm{kDa}$ protein in the wild-type strain of Neurospora crassa. The regulatory mutants $w c-1$ and $w c-2$ are abnormal. J. Photochem. Photobiol. 1990, 5, 95-103.

120. Oda, K.; Hasunuma, K. Light signals are transduced to the phosphorylation of $15 \mathrm{kDa}$ proteins in Neurospora crassa. FEBS Lett. 1994, 345, 162-166.

121. Talora, C.; Franchi, L.; Linden, H.; Ballario, P.; Macino, G. Role of a white collar-1-white collar-2 complex in blue-light signal transduction. EMBO J. 1999, 18, 4961-4968. 
122. Schwerdtfeger, C.; Linden, H. Localization and light-dependent phosphorylation of WHITE COLLAR1 and 2, the two central components of blue light signaling in Neurospora crassa. Eur. J. Biochem. 2003, 22, 4846-4855.

123. Arpaia, G.; Cerri, F.; Baima, S.; Macino, G. Involvement of protein kinase C in the response of Neurospora crassa to blue light. Mol. Gen. Genet. 1999, 262, 314-322.

124. Franchi, L.; Fulci, V.; Macino, G. Protein kinase C modulates light responses in Neurospora by regulating the blue light photoreceptor WC-1. Mol. Microbiol. 2005, 56, 334-345.

125. Franchi, L.; Macino, G. In vitro phosphorylation and kinase assays in Neurospora crassa. Methods Mol. Biol. 2007, 362, 407-412.

126. Schafmeier, T.; Haase, A.; Kaldi, K.; Scholz, J.; Fuchs, M.; Brunner M. Transcriptional feedback of Neurospora circadian clock gene by phosphorylation-dependent inactivation of its transcription factor. Cell 2005, 122, 235-246.

127. Sancar, G.; Sancar, C.; Brunner, M.; Schafmeier, T. Activity of the circadian transcription factor White Collar Complex is modulated by phosphorylation of SP-motifs. FEBS Lett. 2009, 583, 1833-1840.

128. Roux, P.P.; Blenis, J. ERK and p38 MAPK-activated protein kinases: A family of protein kinases with diverse biological functions. Microbiol. Mol. Biol. Rev. 2004, 68, 320-344.

129. Brenna, A.; Grimaldi, B.; Filetici, P.; Ballario, P. Physical association of the WC-1 photoreceptor and the histone acetyltransferase NGF-1 is required for blue light signal transduction in Neurospora crassa. Mol. Biol. Cell 2012, 23, 3863-3872.

130. Grimaldi, B.; Coiro, P.; Filetici, P.; Berge, E.; Dobosy, J.R.; Freitag, M.; Selker, E.U.; Ballario, P. The Neurospora crassa White Collar-1 dependent blue light response requires acetylation of histone H3 lysine 14 by NGF-1. Mol. Biol. Cell 2006, 17, 4576-4583.

131. He, Q.; Shu, H.; Cheng, P.; Chen, S.; Wang, L.; Liu, Y. Light-independent phosphorylation of WHITE COLLAR-1 regulates its function in the Neurospora circadian negative feedback loop. J. Biol. Chem. 2005, 280, 17526-17532.

132. Townsend, R.R.; Lipniunas, P.H.; Tulk, B.M.; Verkman, A.S. Identification of protein kinase A phosphorylation sites on NBD1 and R domains of CFTR using electrospray mass spectrometry with selective phosphate ion monitoring. Protein Sci. 1996, 5, 1865-1873.

133. Tataroğlu, Ö.; Lauinger, L.; Sancar, G.; Jakob, K.; Brunner, M.; Diernfellner, A.C. Glycogen synthase kinase is a regulator of the circadian clock of Neurospora crassa. J. Biol. Chem. 2012, 287, 36936-36943.

134. Schafmeier, T.; Diernfellner, A.; Schafer, A.; Dintsis, O.; Neiss, A.; Brunner, M. Circadian activity and abundance rhythms of the Neurospora clock transcription factor WCC associated with rapid nucleo-cytoplasmic shuttling. Genes Dev. 2008, 22, 3397-3402.

135. Edmondson, D.G.; Roth, S.Y. Chromatinand transcription. FASEB J. 1996, 10, 1173-1182.

136. Narlikar, G.J.; Fan, H.Y.; Kingston, R.E. Cooperation between complexes that regulate chromatin structure and transcription. Cell 2002, 108, 475-487.

137. Allis, C.D.; Berger, S.L.; Cote, J.; Dent, S.; Jenuwien, T.; Kouzarides, T.; Pillus, L.; Reinberg, D.; Shi, Y.; Shiekhattar, R.; et al. New nomenclature for chromatin-modifying enzymes. Cell 2007, 131, 633-636. 
138. Fischle, W.; Wang, Y.; Jacobs, S.A.; Kim, Y.; Allis, C.D.; Khorasanizadeh, S. Molecular basis for the discrimination of repressive methyl-lysine marks in histone H3 by Polycomb and HP1 chromodomains. Genes Dev. 2003, 17, 1870-1881.

139. Strahl, B.D.; Allis, C.D. The language of covalent histone modifications. Nature 2000, 403, 41-45.

140. Jenuwein, T.; Allis, C.D. Translating the histone code. Science 2001, 293, 1074-1080.

141. Naruse, Y.; Oh-hashi, K.; Iijima, N.; Naruse, M.; Yoshioka, H.; Tanaka, M. Circadian and light-induced transcription of clock gene Perl depends on histone acetylation and deacetylation. Mol. Cell. Biol. 2004, 14, 6278-6287.

142. Etchegaray, J.P.; Yang, X.; de Bruyne, J.P.; Peters, A.H.; Weaver, D.R.; Jenuwein, T.; Reppert, S.M. The polycomb group protein EZH2 is required for mammalian circadian clock function. J. Biol. Chem. 2006, 281, 21209-21215.

143. Fu, H.; Maunakea, A.K.; Martin, M.M.; Huang, L.; Zhang, Y.; Ryan, M.; Kim, R.; Lin, C.M.; Zhao, K.; Aladjem, M.I. Methylation of histone H3 on lysine 79 associates with a group of replication origins and helps limit DNA replication once per cell cycle. PLoS Genet. 2013, 9, e1003542.

144. Crosio, C.; Cermakian, N.; Allis, C.D.; Sassone-Corsi, P. Light induces chromatin modification in cells of the mammalian circadian clock. Nat. Neurosci. 2000, 3, 1241-1247.

145. Katada, S.; Sassone-Corsi, P. The histone methyltransferase MLL1 permits the oscillation of circadian gene expression. Nat. Struct. Mol. Biol. 2010, 17, 1414-1421.

146. Jones, M.A.; Covington, M.F.; DiTacchio, L.; Vollmers, C.; Panda, S.; Harmer, S.L. Jumonji domain protein JMJD5 functions in both the plant and human circadian systems. Proc. Natl. Acad. Sci. USA 2010, 107, 21623-21628.

147. Jones, M.A.; Harmer, S. JMJD5 Functions in concert with TOC1 in the Arabidopsis circadian system. Plant Signal. Behav. 2011, 6, 6445-6448.

148. Perales, M.; Más, P. A functional link between rhythmic changes in chromatin structure and the Arabidopsis biological clock. Plant Cell 2007, 19, 2111-2123.

149. Feng, B.; Marzluf, A. Interaction between major nitrogen regulatory protein NIT2 and pathways-specific regulatory factor NIT4 is required for their synergistic activation of gene expression in Neurospora crassa. Mol. Cell. Biol. 1998, 18, 3983-3990.

150. Baima, S.; Macino, G.; Morelli, G. Photoregulation of the albino-3 gene in Neurospora crassa. J. Photochem. Photobiol. 1991, 11, 107-115.

151. Etchegaray, J.P.; Lee, C.; Wade, P.A.; Reppert, S.M. Rhythmic histone acetylation underlies transcription in the mammalian circadian clock. Nature 2003, 421, 177-182.

152. Carrozza, M.J.; Utley, R.T.; Workman, J.L.; Cote, J. The diverse functions of histone acetyltransferase complexes. Trends Genet. 2003, 19, 321-329.

153. Belden, W.J.; Loros, J.J.; Dunlap, J.C. Execution of the circadian negative feedback loop in Neurospora requires the ATP-dependent chromatin-remodeling enzyme CLOCK SWITCH. Mol. Cell 2007, 25, 587-600.

154. Crosson, S.; Moffat, K. Photoexcited structure of a plant photoreceptor domain reveals a light-driven molecular switch. Plant Cell 2002, 14, 1067-1075.

155. Savkur, R.S.; Burris, T.P. The coactivator LXXLL nuclear receptor recognition motif. J. Pept. Res. 2004, 63, 207-212. 
156. Schmutz, I.; Ripperger, J.A.; Baeriswyl-Aebischer, S.; Albrecht, U. The mammalian clock component PERIOD2 coordinates circadian output by interaction with nuclear receptors. Genes Dev. 2010, 24, 345-357.

157. Näär, A.M.; Thakur, J.K. Nuclear receptor-like transcription factors in fungi. Genes Dev. 2009, 23, 419-432.

158. Belden, W.J.; Lewis, Z.A.; Selker, E.U.; Loros, J.J.; Dunlap, J.C. CHD1 remodels chromatin and influences transient DNA methylation at the clock gene frequency. PLoS Genet. 2011, 7, e1002166.

159. Ruesch, C.E.; Ramakrishnan, M.; Park, J.; Li N.; Chong, H.S.; Zaman, R.; Joska, T.M.; Belden, W.J. The histone H3 lysine 9 methyltransferase DIM-5 modifies chromatin at frequency and represses light-activated gene expression. Genes Genomes Genet. 2014, 1, 93-101.

160. Selker, E.U.; Tountas, N.A.; Cross, S.H.; Margolin, B.S.; Murphy, J.G.; Bird, A.P.; Freitag, M. The methylated component of the Neurospora crassa genome. Nature 2003, 422, 893-897.

161. Lewis, Z.A.; Honda, S.; Khlafallah, T.K.; Jeffress, J.K.; Freitag, M.; Mohn, F.; Schübeler, D.; Selker, E.U. Relics of repeat-induced point mutation direct heterochromatin formation in Neurospora crassa. Genome Res. 2009, 19, 427-437.

162. Cha, J.; Zhou, M.; Liu, Y. CATP is a critical component of the Neurospora circadian clock by regulating the nucleosome occupancy rhythm at the frequency locus. EMBO Rep. 2013, 14, 923-930.

163. Raduwan, H.; Isola, A.L.; Belden, W.J. Methylation of histone H3 on lysine 4 by the lysine methyltransferase SET1 protein is needed for normal clock gene expression. J. Biol. Chem. 2013, 288, 8380-8390.

164. Miller, T.; Krogan, N.J.; Dover, J.; Erdjument-Bromage, H.; Tempst, P.; Johnston, M.; Greenblatt, J.F.; Shilatifard, A. COMPASS: A complex of proteins associated with a trithorax-related SET domain protein. Proc. Natl. Acad. Sci. USA 2001, 98, 12902-12907.

165. Barski, A.; Cuddapah, S.; Cui, K.; Roh, T.Y.; Schones, D.E.; Wang, Z.; Wei, G.; Chepelev, I.; Zhao, K. High-resolution profiling of histone methylations in the human genome. Cell 2007, 129, 823-837.

166. Lee, C.; Etchegaray, J.P.; Cagampang, F.R.; Loudon, A.S.; Reppert, S.M. Posttranslational mechanisms regulate the mammalian circadian clock. Cell 2001, 107, 855-867.

167. Brunner, M.; Kaldi, K. Interlocked feedback loops of the circadian clock of Neurospora crassa. Mol. Microbiol. 2008, 68, 255-262.

168. Wang, B.; Kettenbach, A.N.; Gerber, S.A.; Loros, J.J; Dunlap, J.C. Neurospora WC-1 recruits SWI/SNF to remodel frequency and initiate a circadian cycle. PLoS Genet. 2014, 9, e1004599.

169. Clapier, C.R.; Cairns, B.R. The biology of chromatin remodeling complexes. Annu. Rev. Biochem. 2009, 78, 273-304.

170. De la Serna, I.L.; Ohkawa, Y.; Imbalzano, A.N. Chromatin remodelling in mammalian differentiation: Lessons from ATP-dependent remodellers. Nat. Rev. Genet. 2006, 6, 461-473.

171. Nishiwaki, T.; Iwasaki, H.; Ishiura, M.; Kondo, T. Nucleotide binding and autophosphorylation of the clock protein KaiC as a circadian timing process of cyanobacteria. Proc. Natl. Acad. Sci. USA 2000, 97, 495-498.

172. Nakajima, M.; Imai, K.; Ito, H.; Nishiwaki, T.; Murayama, Y.; Iwasaki, H.; Oyama, T.; Kondo, T. Reconstitution of circadian oscillation of cyanobacterial KaiC phosphorylation in vitro. Science 2005, 15, 414-415. 
173. Iwasaki, H.; Nishiwaki, T.; Kitayama, Y.; Nakajimam, M.; Kondo, T. KaiA-stimulated KaiC phosphorylation in circadian timing loops in cyanobacteria. Proc. Natl. Acad. Sci. USA 2002, 99, 15788-15793.

174. Edery, I.; Zwiebel, L.J.; Dembinska, M.E.; Rosbash, M. Temporal phosphorylation of the Drosophila period protein. Proc. Natl. Acad. Sci. USA 1994, 91, 2260-2264.

175. Lin, J.M.; Schroeder, A.; Allada, R. In vivo circadian function of casein kinase 2 phosphorylation sites in Drosophila PERIOD. J. Neurosci. 2005, 25, 11175-11183.

176. Baker, C.L.; Dunlap, J.C. Circadian rhythms: Phosphorylating the CLOCK. Cell Cycle 2010, 9, 231-232.

177. Kondratov, R.V.; Chernov, M.V.; Kondratova, A.A.; Gorbacheva, V.Y.; Gudkov, A.V.; Antoch, M.P. BMAL1-dependent circadian oscillation of nuclear CLOCK: Posttranslational events induced by dimerization of transcriptional activators of the mammalian clock system. Genes Dev. 2003, 17, 1921-1932.

178. Spengler, M.L.; Kuropatwinski, K.K.; Schumer, M.; Antoch, M.P. A serine cluster mediates BMAL1-dependent CLOCK phosphorylation and degradation. Cell Cycle 2009, 8, 4138-4146.

179. Yoshitane, H.; Takao, T.; Satomi, Y.; Du, N.H.; Okano, T.; Fukada, Y. Roles of CLOCK phosphorylation in suppression of E-box-dependent transcription. Mol. Cell. Biol. 2009, 29, 3675-3686.

180. Vanselow, K.; Kramer, A. Role of phosphorylation in the mammalian circadian clock. Cold Spring Harb. Symp. Quant. Biol. 2007, 72, 167-176.

181. Dardente, H.; Fortier, E.E.; Martineau, V.; Cermakian, N. Cryptochromes impair phosphorylation of transcriptional activators in the clock: A general mechanism for circadian repression. Biochem. J. 2007, 402, 525-536.

182. Vollmers, C.; Schmitz, R.J.; Nathanson, J.; Yeo, G.; Ecker, J.R.; Panda, S. Circadian oscillations of protein-coding and regulatory RNAs in a highly dynamic mammalian liver epigenome. Cell Metab. 2012, 16, 833-845.

(C) 2015 by the authors; licensee MDPI, Basel, Switzerland. This article is an open access article distributed under the terms and conditions of the Creative Commons Attribution license (http://creativecommons.org/licenses/by/4.0/). 